\title{
The effect of temperature on the failure modes of polymer foam cored sandwich structures
}

S.Zhang $\cdot$ J.M. Dulieu-Barton* $\cdot$ O.T. Thomsen

Faculty of Engineering and the Environment, University of Southampton, Highfield, SO17 1BJ, UK

*Corresponding author: janice@soton.ac.uk

\begin{abstract}
The influence of elevated temperature on the stability of sandwich structures is investigated. A new analytical solution is proposed that enables the calculation of the critical wrinkling stress in sandwich beams subjected to load and elevated temperatures. The effect of a through thickness temperature gradient is accounted for by imposing different stiffnesses of the core for the different temperatures. The sandwich beam studied in the paper is loaded in a simply supported four-point bending configuration, where one of the face sheets is heated. The experimental approach utilises high-speed imaging where the strains are calculated from measured displacements obtained from digital image correlation (DIC). A shift of the failure mode from face sheet yielding to face sheet wrinkling is observed with increasing temperatures. The results from the new analytical method agree well with corresponding experimental results. Finite element analysis is also conducted, which shows excellent correspondence with the theory and the experimental data. The work clearly demonstrates that under certain conditions the load response of the sandwich beam can become nonlinear and unstable, and hence will fail well below face sheet yielding load because of the loss of stiffness of the core material.
\end{abstract}

Keywords: foam cored sandwich structures, thermal degradation, failure modes, wrinkling

\section{Introduction}

At present, polymer foam cored sandwich structures are being used increasingly in applications such as marine structures and wind turbine blades. In service, sandwich structure components are frequently exposed to solar radiation which results in elevated surface temperature in the range of 50 $100^{\circ} \mathrm{C}$ [1]. Under these conditions the mechanical properties of the face sheet material (e.g. aluminium alloy or glass fibre reinforced polymer, GFRP) are barely affected. However, the polymer core materials become much softer [2,3], losing both stiffness and strength. As the core material in 
Zhang, S., Dulieu-Barton, J.M., and Thomsen, O.T., "The effect of temperature on the failure modes of polymer foam cored sandwich structures", Composite Structures, 121, 2015, 104-113.

sandwich structures subjected to bending and shear loading carries transverse shear stresses and stabilises the face sheets, it is clear that the mechanical behaviour of sandwich structures will be affected by the elevated temperature.

When the sandwich structure is subjected to a uniformly elevated temperature, classical sandwich analyses are capable of predicting the mechanical behaviour, if the face sheet and core material properties at elevated temperatures are known. However, defining the mechanical behaviour becomes much more complex if a temperature gradient exists through the thickness of the material (e.g. solar radiation on only one surface), as the face sheet and particularly the core may possess inhomogeneous mechanical properties. Frostig and Thomsen [4-6] used high order sandwich panel theory (HSAPT) to demonstrate that bending, buckling and free vibration of sandwich structures can all be affected significantly when the sandwich structure is exposed to a through thickness temperature gradient. They showed that the load-deflection behaviour of the sandwich assembly may shift from being linear and stable to non-linear and unstable above certain temperatures. Birman [7], who used a third-order shear deformation theory combined with an 'equivalent stiffness' method, also predicted that face sheet wrinkling may become the dominant failure mode at elevated temperatures. These analyses attribute this instability to core material property degradation, the thermal induced stresses (if the thermal expansion is constrained) and also possible face sheet degradation at higher temperatures. It is important to notice that in [4-7] there were no experimental validations to confirm the onset of the unstable behaviour and thereby understand better the thermomehcanical interaction effects, i.e. the nonlinear interactions that develop due to the combined simultaneous action of thermal and mechanical loads.

The objective of the present research is to conduct an experimentally based investigation on how the elevated temperature affects the stability of sandwich structures. In particular, the study aims to assess if face sheet wrinkling or localised buckling may occur at lower mechanical load levels due to elevated temperatures. To guide the design of the experiment, a modification of Plantema's wrinkling analysis [8] is proposed to calculate the critical wrinkling stress which accounts for the through thickness temperature gradient by imposing inhomogeneous material properties in the core. This approach is considered to be more accurate than using a modification of Hoff and Mautner's wrinkling analysis [7], as the assumption that the wrinkling wave decays exponentially through the thickness of the core away from the wrinkled/buckled face adopted in [7] is more realistic than the simple linear decay proposed by Hoff and Mautner. The experimental work described later in the present paper confirms that Plantema's approach is in fact more realistic. The decay of the wrinkling wave must be correctly defined because it dictates the distribution of the elastic strain energy through the thickness of the sandwich structure and thereby the critical instability load values. 
Zhang, S., Dulieu-Barton, J.M., and Thomsen, O.T., "The effect of temperature on the failure modes of polymer foam cored sandwich structures", Composite Structures, 121, 2015, 104-113.

To demonstrate the new theory it was decided to use a four-point bending configuration rather than the normally used in-plane compression testing configuration [9], as imposing a transverse temperature gradient in a test specimen under compression loading introduces significant asymmetrical deformations and material properties. Thus it is very difficult to ensure an identical loading on each face sheet. A range of temperatures is studied from room temperature $25^{\circ} \mathrm{C}$ to $90^{\circ} \mathrm{C}$ (just beyond the glass transition temperature of the polymer foam). In the experimental work DIC (digital image correlation) [10] was used to obtain the deformation of the sandwich beam specimen. High speed imaging was used to capture the localised wavy buckle deformation associated with wrinkling as the instability rapidly generates material plastic deformation and face sheet failure.

\section{A modification of Plantema's wrinkling analysis}

Local face sheet instability or wrinkling may occur when sandwich structures are subjected to ordinary bending or in-plane compression, where at least one face sheet carries a compressive stress. Once wrinkling occurs, the face sheet buckles in short waves and generally the sandwich structure cannot withstand further loading. The compressive stress in the face sheet that induces wrinkling is known as the critical wrinkling stress. Allen [11], Plantema [8] and Hoff and Mautner [12] used different approaches to define the critical wrinkling stress. For the case of an isotropic face sheet, where the core is much thicker than the face sheet, an expression of the following form is derived:

$$
\sigma_{c r}=C \sqrt[3]{E_{f} E_{c} G_{c}}
$$

where $\sigma_{c r}$ is the critical wrinkling stress, $E_{f}$ is Young's modulus of the face sheet, $E_{c}$ and $G_{c}$ are the Young's modulus and shear modulus of the core, respectively. $C$ is a constant which is obtained as 0.78 by Allen, 0.825 by Plantema and 0.91 by Hoff and Mautner.

All the analyses $[8,11,12]$ assume that the core is homogenous through the thickness. However, if there is a temperature gradient through the thickness of the core, the material properties will not be homogenous, specifically the Young's modulus and the shear modulus as these vary significantly with temperature. Therefore Equation (1) must be modified to account for the variation of the core moduli due to a through thickness temperature gradient. Birman [7] proposed a modification of Hoff and Mautner's wrinkling analysis that accounts for the core stiffness variation in the through thickness direction. It was suggested that a 'core equivalent stiffness' was used to replace $E_{c}$ and $G_{c}$ in Equation (1). The assumption was made that the core closer to the wrinkling face sheet has to withstand a greater proportion of the wrinkling dependent on the distance from the face sheet. This is a reasonable assumption but its validity was not determined either by comparing with experimental or FEA results. In the experimental work described later in the present paper it is shown that an exponential function (as used by Plantema [8]) describes the nature of the decay of the wrinkling deformation better than a 
Zhang, S., Dulieu-Barton, J.M., and Thomsen, O.T., "The effect of temperature on the failure modes of polymer foam cored sandwich structures", Composite Structures, 121, 2015, 104-113.

linear fit (as used by Hoff and Mautner [12]). Hence the analytical approach described below is based on Plantema's wrinkling analysis.

A schematic of face sheet wrinkling is shown in Figure 1. Both the face sheet and the core are assumed to have a unit width. The face sheet is subjected to a compressive load $F$, and hence the compressive stress of the face sheet is $F / t_{f}$, where $t_{f}$ is the thickness of the face sheet. The amplitude of the wrinkling wave is denoted by $W$, and the half wavelength is denoted by $l$. The face sheet is assumed to be isotropic, and with a Young's modulus $E_{f}$. The face sheet is also assumed perfectly flat before wrinkling. $E_{c}(z)$ and $G_{c}(z)$ are the Young's modulus and shear modulus of the core, which are functions of the through thickness coordinate $z$. If the through thickness variation of temperature is known, and the dependency between the elastic moduli of the core and temperature is known, then the variation of $E_{\mathcal{c}}, G_{c}$ through the core thickness can be derived. Here, $E_{c}(z)$ and $G_{c}(\mathrm{z})$ are represented by general polynomial series expansions in terms of $z$ :

$$
\begin{aligned}
& E_{c}(z)=E_{c} *\left(1+a_{1} z+a_{2} z^{2}+\ldots .+a_{n} z^{n}\right)=E_{c}\left(1+\sum_{1}^{n} a_{n} z^{n}\right) \\
& G_{c}(z)=G_{c} *\left(1+a_{1} z+a_{2} z^{2}+\ldots .+a_{n} z^{n}\right)=G_{c}\left(1+\sum_{1}^{n} a_{n} z^{n}\right)
\end{aligned}
$$

where the coefficients $a_{n}$ are constants.

By assuming that the amplitude of the wrinkling wave varies harmonically in the longitudinal direction, and decays exponentially through the core thickness away from the wrinkled face, as in [8] the following expression is obtained:

$$
w(x, z)=W e^{-k z} \sin \frac{\pi x}{l}
$$

where $k$ is a constant which reflects the rate of decay of the wrinkling wave amplitude in terms of the through thickness coordinate $z$.

If it is further assumed that the wrinkling does not cause any displacement in the $x$ direction, the core normal stress and shear stress resulting from the wrinkling are expressed as follows:

$$
\begin{gathered}
\sigma_{c z}=E_{c}(z) \frac{\partial w}{\partial z}=-k E_{c}(z) W e^{-k z} \sin \frac{\pi x}{l} \\
\tau_{c z}=G_{c}(z) \frac{\partial w}{\partial x}=G_{c}(z) W e^{-k z} \frac{\pi}{l} \cos \frac{\pi x}{l}
\end{gathered}
$$

Hence, strain energy stored in the core $\left(U_{c}\right)$ due to the core deformation is: 
Zhang, S., Dulieu-Barton, J.M., and Thomsen, O.T., "The effect of temperature on the failure modes of polymer foam cored sandwich structures", Composite Structures, $\underline{121}, 2015,104-113$.

$$
\begin{aligned}
& U_{c}=\int_{0}^{l} \int_{0}^{t_{c}} \frac{\sigma_{c z}^{2}}{2 E_{c}(z)} d z d x+\int_{0}^{l} \int_{0}^{t_{c}} \frac{\tau_{c z}^{2}}{2 G_{c}(z)} d z d x \\
& =\frac{W^{2} k l}{8} \int_{0}^{t_{c}} 2 k E_{c}(z) e^{-2 k z} d z+\frac{\pi^{2} W^{2}}{8 k l} \int_{0}^{t_{c}} 2 k G_{c}(z) e^{-2 k z} d z
\end{aligned}
$$

The bending strain energy in the buckled face sheet $\left(U_{f}\right)$ is obtained as [7]:

$$
U_{f}=\frac{D_{f}}{2} \int_{0}^{l}\left(\frac{d^{2} w_{f}}{d x^{2}}\right)^{2} d x=\frac{W^{2} D_{f} \pi^{4}}{4 l^{3}}
$$

where $D_{f}$ is the bending stiffness of the face sheet.

The change of potential energy of the external load $\left(U_{F}\right)$ is [7]:

$$
U_{F}=-\frac{1}{2} \int_{0}^{l} F\left(\frac{d w_{f}}{d x}\right)^{2} d x=-\frac{F W^{2} \pi^{2}}{4 l}
$$

The total potential energy $(U)$ is the sum of Equations (5), (6) and (7), i.e.:

$$
U=\frac{W^{2} D_{f} \pi^{4}}{4 l^{3}}+\frac{W^{2} k l}{8} \int_{0}^{t_{c}} 2 k E_{c}(z) e^{-2 k z} d z+\frac{\pi^{2} W^{2}}{8 k l} \int_{0}^{t_{c}} 2 k G_{c}(z) e^{-2 k z} d z-\frac{F W^{2} \pi^{2}}{4 l}
$$

Following the approach used in [7] and minimising $U$ with respect to $W$, a nontrivial solution is obtained:

$$
F=\frac{\pi^{2} D_{f}}{l^{2}}+\frac{k l^{2}}{2 \pi^{2}} \int_{0}^{t_{c}} 2 k E_{c}(z) e^{-2 k z} d z+\frac{1}{2 k} \int_{0}^{t_{c}} 2 k G_{c}(z) e^{-2 k z} d z
$$

It can be seen that Equation (9) gives $F$ as a function of both the decay rate, $k$, and the half wave length of the wrinkle, $l$. Therefore to identify a minimum value of $F$ it is necessary firstly to differentiate Equation (9) with respect to $l$ and equate to zero to give a value of $l$ for the critical wrinkling load:

$$
l=\pi \sqrt[4]{\frac{D_{f}}{k^{2} \int_{0}^{t_{c}} E_{c}(z) e^{-2 k z} d z}}
$$

Equation (10) indicates that the wavelength of the wrinkle is dependent on the Young's modulus of the core and the bending stiffness of the face sheet, but independent of the shear modulus of the core.

By substituting Equation (10) into Equation (9) a value for $F$ is obtained that is only independent of $l$ i.e.: 
Zhang, S., Dulieu-Barton, J.M., and Thomsen, O.T., "The effect of temperature on the failure modes of polymer foam cored sandwich structures", Composite Structures, $\underline{121}, 2015,104-113$.

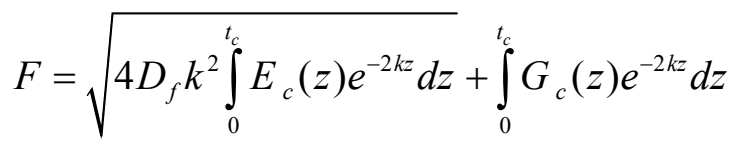

Then by differentiating Equation (11) with respect to $k$ and equating to zero it is possible to establish the critical wrinkling load $\left(F_{c r}\right)$. The resulting expression has the form of an implicit equation, and accordingly it is not possible to derive closed form analytical expression for $F_{c r}$. However, as Equation (11) contains only one variable $k$ (i.e. the decay rate in Equation (3)), the critical wrinkling load $F_{c r}$ can be conveniently identified using an iterative method such as the simple loop searching method available in MATLAB ${ }^{\mathrm{TM}}$. Once $F_{c r}$ is established then the critical wrinkling stress can be obtained as $\sigma_{c r}=F_{c r} / t_{f}$. Hence it is possible to use Equation (11) as a basis for designing an experiment that provokes wrinkling behaviour under the combined action of both mechanical in-plane and thermal loading, which is described in the following sections of the present paper.

\section{Loading configuration design}

\subsection{Selection of loading approach}

A commonly used experimental approach to investigate the wrinkling behaviour of sandwich structures is to introduce in-plane compressive load on a sandwich plate or beam specimen [9]. However, this loading configuration was considered to be unsuitable for investigating the wrinkling behaviour of sandwich structures with a through thickness temperature gradient. This is because when an asymmetric temperature gradient exists through the specimen thickness (e.g. one face sheet is at a high temperature and the other face sheet is at a low temperature), the asymmetric thermal expansion results in an overall bending of the specimen, thereby making it excessively difficult to ensure an identical compressive loading on each face sheet. The curvature due to the asymmetric thermal expansion could also promote a failure by global buckling rather than wrinkling or localised buckling. Moreover, the theory assumes that the face sheet is flat and the compressive load is aligned with the face sheet, which is difficult to achieve in practice. Simply ensuring the compressive load is applied uniformly across the width of the face sheet requires a specially designed rig that accounts for possible small inclinations in the face sheet edges and misalignment of the test machine. Finally, the asymmetric through thickness heating of the sandwich specimen will affect the constituent materials by softening the material volumes subjected to the warmer temperatures, where especially the polymer foam core is sensitive to thermal softening. Therefore a four point bending loading configuration was used, that is straightforward to set up in a reproducible manner.

The four-point bending set-up used in this work is shown in Figure 2. The face sheets are heated to different temperatures to generate a temperature gradient through the specimen thickness (the method of heating is described in detail in section 5). With a transverse load, $P$, as shown in Figure 2, the top 
Zhang, S., Dulieu-Barton, J.M., and Thomsen, O.T., "The effect of temperature on the failure modes of polymer foam cored sandwich structures", Composite Structures, 121, 2015, 104-113.

face sheet carries a compressive stress and the bottom face sheet carries a tensile stress in the $x$ direction, thus face sheet wrinkling can only occur at the top face sheet. Hence, the specimen is not required to be symmetric about the mid-plane in terms of thermal expansion or material properties avoiding the aforementioned difficulties arising from asymmetry for in-plane compression loading. Although the face sheet near the mid-span is not perfectly flat as assumed in the analytical model but with a slight bending curvature due to the external loading, the bending curvature is very small compared to the short wave length of the wrinkle. Therefore, it is assumed that Equation (11) is still applicable. The main difficulty with the bending configuration is the local indentation at the loading points. This was mitigated by introducing stiff rubber loading pads with an aluminium alloy facing to prevent localised indentation and damage.

\subsection{Specimen material and geometry}

Aluminium alloy (AA7075-T6) was selected as the face sheet material because of its large heat conductivity and because its stiffness and strength are virtually independent of temperature over the range applicable in the current work. Moreover this alloy has a large yield strength, which means that it is possible to design a specimen to fit the size limitations of a standard test machine so that wrinkling occurs before yielding. Thus, the influence of core stiffness reduction (softening) due to elevated temperature on the overall sandwich structure behaviour can be separately investigated. Mechanical properties (Young's modulus, Poisson's ratio and yield strength) of the aluminium alloy were tested at different temperatures in reference to ASTM standard E8 [13]. The stress-strain curves of the AA7075-T6 obtained at different temperatures are shown in Figure 2. It can be seen that both the Young's modulus and the yield strength reduce slightly with increasing temperatures. At $90^{\circ} \mathrm{C}$, about $5 \%$ of the Young's modulus and $8 \%$ of the yield strength are lost in comparison to the corresponding values at $25^{\circ} \mathrm{C}$. Test results for the Young's modulus and Poisson's ratio at room temperature $\left(25^{\circ} \mathrm{C}\right)$ are listed in Table 1 . The results show a good agreement with the observations in [14], which investigated the temperature dependence of aluminium alloys AA2024 and AA7805.

Table 1: Material properties at room temperature $\left(25^{\circ} \mathrm{C}\right)$

\begin{tabular}{|l|l|l|l|l|}
\hline & $E_{\mathrm{z}}(\mathrm{MPa})$ & $E_{\mathrm{x}}(\mathrm{MPa})$ & $G_{\mathrm{zx}}(\mathrm{MPa})$ & $v_{\mathrm{zx}}$ \\
\hline AA7075-T6 & 69100 & 69100 & 26576 & 0.3 \\
\hline Divinycell H100 & 132 & 58 & 32 & 0.4 \\
\hline
\end{tabular}

The core material was chosen as Divinycell H100 PVC foam manufactured by DIAB Sweden. The Divinycell H100 foam core is representative of a very large range of cross-linked rigid PVC foam cores used in a wide range of structural applications. Detailed characterisation of the elastic properties of Divinycell $\mathrm{H} 100$ at elevated temperatures $\left(25^{\circ} \mathrm{C}\right.$ to $\left.90^{\circ} \mathrm{C}\right)$ have been conducted in $[3,15]$. The 
Zhang, S., Dulieu-Barton, J.M., and Thomsen, O.T., "The effect of temperature on the failure modes of polymer foam cored sandwich structures", Composite Structures, 121, 2015, 104-113.

reduction of the Young's and shear moduli with increasing temperature (i.e. the thermal degradation) were found to be identical and can be approximately expressed using a third-order polynomial [3]:

$\frac{E(T)}{E\left(T_{0}\right)}=\frac{G(T)}{G\left(T_{0}\right)}=-3.1943 * 10^{-6} T^{3}+4.2436 * 10^{-4} T^{2}-2.2653 * 10^{-2} T+1.3626$

where $E(T)$ and $G(T)$ represent the Young's and shear moduli of Divinycell H100 at temperature $T$, respectively. $T_{0}$ represents the room temperature $\left(25^{\circ} \mathrm{C}\right)$. The Young's and shear moduli of Divinycell $\mathrm{H} 100$ at the room temperature are listed in Table 1, which is all that is required as an input into Equation (12).

To ensure that wrinkling will occur during the experiment, the specimen dimensions and loading span were established using Equation (11) as a guide. The temperature condition was defined so that the top face sheet temperature varies from $25^{\circ} \mathrm{C}$ to $90^{\circ} \mathrm{C}$ and the bottom face sheet stays at room temperature $\left(25^{\circ} \mathrm{C}\right)$. The temperature gradient through the core was assumed to be linear as has been experimentally observed in [16]. The temperature through the face sheet thickness was deemed to be uniform due to the good heat conductivity of aluminium alloy as well as the small thickness.

Because of the restriction of the test machine used in the experimental work the length of the specimen was selected to be $600 \mathrm{~mm}$. The thickness of the face sheet and core were chosen to be 0.3 $\mathrm{mm}$ and $15 \mathrm{~mm}$, respectively. The width was chosen as $50 \mathrm{~mm}$ which is 3.2 times the beam thickness and $1 / 12$ of the beam length, thus a quite uniform beam flexure through the width is guaranteed [17]. The loading span $L_{1}$ and $L_{2}$ (see Figure 2) was chosen to be $275 \mathrm{~mm}$ and $100 \mathrm{~mm}$, respectively. For this specimen configuration, the critical wrinkling stress of the specimen obtained using the modification of Plantema's wrinkling analysis is plotted against the temperature of the top face sheet $\left(T_{t}\right)$ in Figure 4. It can be seen that the critical wrinkling stress decreases as the temperature of the top face sheet increases, with a very steep reduction beyond $70^{\circ} \mathrm{C}$. The yield strength of the aluminium face sheet at $25^{\circ} \mathrm{C}, 50^{\circ} \mathrm{C}, 70^{\circ} \mathrm{C}$ and $90^{\circ} \mathrm{C}$ obtained from Figure 3 for $0.2 \%$ plastic strain are also shown in Figure 4. The compressive yield strength of the aluminium alloy is assumed identical to the tensile yield strength [18]. For this particular specimen, it can be seen that the predicted critical wrinkling stress is larger than the face sheet yield strength below $58^{\circ} \mathrm{C}$ so the failure mode will be face sheet yielding. Above $58^{\circ} \mathrm{C}$ face sheet wrinkling is predicted to be the failure mode. As the beam is very long core shear failure is eliminated in the sections $L_{1}$.

\section{Finite element analysis}

2D finite element models including geometric nonlinearity but assuming linear elastic material behaviour were constructed to compare with the prediction of the modification of Plantema's wrinkling analysis, using the commercially available software ANSYS 13.0. The model was chosen to 
Zhang, S., Dulieu-Barton, J.M., and Thomsen, O.T., "The effect of temperature on the failure modes of polymer foam cored sandwich structures", Composite Structures, 121, 2015, 104-113.

assume linear elastic material behaviour for simplicity, and as it is known wrinkling is typically initiated by elastic instability. The geometrical model, mesh, constraints and load introduction are shown in Figure 5. As the specimen deforms symmetrically about the mid-span in the simply supported 4-point bending configuration, a half beam model was adopted here. The foam volume was modelled using 8-node orthotropic elements, while the aluminium face sheet and loading pad were modelled using 8-node isotropic elements. Finer size elements were used for the area near the midspan to accommodate the large rotations and deformations that occur during face sheet wrinkling. In this region, the face sheet element size was chosen as $0.5 \mathrm{~mm} \times 0.3 \mathrm{~mm}(x \times z)$, and the foam element size was chosen as $0.5 \mathrm{~mm} \times 0.5 \mathrm{~mm}(x \times z)$. For the area away from the mid-span, coarser elements were used where the face sheet element size was chosen as $2 \mathrm{~mm} \times 0.3 \mathrm{~mm}(x \times z)$, and the foam element size was chosen as $2 \mathrm{~mm} \times 0.5 \mathrm{~mm}(x \times z)$. To model exactly the experimental arrangements the rubber loading blocks were included; these were assumed to be isotropic with a Young's modulus of $4 \mathrm{MPa}$ obtained from tensile tests on strips of the rubber material. A concentrated load $(P / 2)$ was introduced at the middle of the top surface of loading pad. The nodes at beam mid-span (the right edge in Figure 5) were fixed in the $x$ direction, and the node at the support position (left in Figure 5) was fixed in the $z$ direction. Material properties as given in Table 1 and Equation (12) were used as inputs to the FE model. To enable face sheet wrinkling near the mid-span, geometrical nonlinear deformations were enabled in the FE solving procedure, and the load $(P / 2)$ was imposed in steps. An elaborate mesh convergence study concerning the mid-span deflection at each load step was conducted to ensure that a fully converged nonlinear FE solution was obtained. Thus, a small load increment ( $2 \%$ of the load predicted to trigger wrinkling) was used at each load step, and this led to a converged solution.

A typical solution from the FE model is shown in Figure 6. Here the temperature of the model is held constant and homogeneous at $25^{\circ} \mathrm{C}$, i.e. at room temperature, so that initial comparisons can be made with the theory given in [7] to validate the model. Figure 6(a) shows the relationship between the deflection at the mid-span of the top face sheet and the load $(P / 2)$. It can be seen that the deflection initially increases proportionally with the load indicating that the sandwich beam deforms geometrically linearly in this region. From point 'B', the load-deflection curve becomes nonlinear, and it is observed that the deflection increases significantly with a very small increase of the load. Figure 6(b) shows a plot showing the deformed prebuckled state and the corresponding contours of the through thickness normal stress $\left(\sigma_{z}\right)$ for a small load; point A in Figure 6(a). It is observed that the through thickness stresses are practically uniform, and effectively zero even under the loading pad; indicating its effectiveness in spreading the load. Figure 6(c) shows the deformed state at the wrinkling initiation load level as well as the contours of $\sigma_{z}$ at point 'B'. The alternating tensile and compressive stresses observed in the core underneath the top face sheet result from the wavy deflection pattern of the top face sheet, i.e. the wrinkling. This wavy deflection is more evident at ' $\mathrm{C}$ ' 
Zhang, S., Dulieu-Barton, J.M., and Thomsen, O.T., "The effect of temperature on the failure modes of polymer foam cored sandwich structures", Composite Structures, 121, 2015, 104-113.

as is clearly shown Figure 6(d). Thus, the FE model has shown the occurrence of face sheet wrinkling when the compressive stress of face sheet reaches to a certain value (point ' $B$ ' in Figure 6(a)), i.e. the critical wrinkling stress, $\sigma_{c r}$. The critical wrinkling stress was obtained as $-547 \mathrm{MPa}$ from the $\mathrm{FE}$ model. This value agrees very well with that calculated by Plantema's wrinkling theory (see Equation (1)) of $-552 \mathrm{MPa}$. It is now pe to use the model to assess the accuracy of the proposed new theory described in section 2 by introducing a through the thickness temperature gradient in the model and hence inhomogeneous core elastic properties. In addition to the fully geometrically nonlinear FE analysis described above, linear bifurcation buckling analysis using the 'buckle' mode in ANSYS was also conducted. This analysis yields the critical instability load and the corresponding wrinkling pattern, but no information about the post buckled stage. The critical wrinkling stress obtained by the linear bifurcation analysis in ANSYS is equal to the results that are shown in Figure 7, and the wrinkling pattern obtained is the same as that shown in Figure 6(d) obtained through the nonlinear FE analysis.

The critical wrinkling stresses of the sandwich beam specimen loaded in 4-point bending and with a linear through thickness temperature gradient over a range of top face sheet temperatures from $25^{\circ} \mathrm{C}$ to $90^{\circ} \mathrm{C}$, and where the bottom face sheet was held constant at $25^{\circ} \mathrm{C}$ were obtained from the nonlinear FE model. These are shown in Figure 7 plotted against the top face sheet temperature, and shown alongside the values predicted by the modified Plantema wrinkling analysis discussed in section 2 (solving Equation (11) iteratively in MATLAB). Figure 7 shows that the critical wrinkling stresses derived from the modified Plantema wrinkling analysis agrees very well with those obtained from the FE model. In fact the difference between the two data sets is less than $2 \%$.

\section{Experimental procedure and deformation measurement}

Sandwich panels with a size of $600 \mathrm{~mm}$ x $600 \mathrm{~mm}$ (length $\mathrm{x}$ width) were manufactured by bonding two aluminium sheets (AA7075-T6) and one foam block (Divinycell H100) using an adhesive film SA80 provided by Gurit UK. To enhance the bonding toughness, the surface of the aluminium sheet was carefully abraded and cleaned before being bonded. The adhesive film was cured under uniform pressure introduced by a vacuum bag to ensure a uniform bond line with low voids. The adhesive was cured at $80^{\circ} \mathrm{C}$ for a duration of 12 hours. The glass transition temperature of the SA80 adhesive is $112^{\circ} \mathrm{C}$, thereby the degradation of its mechanical properties is not expected to be significant within the temperature range considered in this work. Hence, the influence of the thermal degradation of the Young's modulus of the adhesive bond on the wrinkling behaviour is insignificant. Sandwich beam specimens with a width of $50 \mathrm{~mm}$ were cut from the cured sandwich panels. The adhesive layer was measured to be approximately $0.1 \mathrm{~mm}$ thick, which is very thin in comparison to the core thickness 
Zhang, S., Dulieu-Barton, J.M., and Thomsen, O.T., "The effect of temperature on the failure modes of polymer foam cored sandwich structures", Composite Structures, 121, 2015, 104-113.

$(15 \mathrm{~mm})$ and hence is considered negligible in the analysis of the mechanical behaviour of the sandwich beam.

The sandwich beam specimens were loaded by a simply supported four-point bending jig mounted in an Instron 8502 servo-hydraulic test machine as shown in Figure 8. The top span $\left(L_{2}\right)$ of the specimen was selected as $100 \mathrm{~mm}$ and the bottom span $\left(2 L_{1}+L_{2}\right)$ was $550 \mathrm{~mm}$. A $5 \mathrm{kN}$ load cell was fixed on the test machine to record the load data $(P)$. The top face sheet was heated by an infrared lamp, while the bottom face sheet was exposed to the ambient temperature. Thus a temperature gradient was introduced through the specimen thickness. During the heating process, the side surfaces of the specimen were insulated using polymer foam shields to minimise the heat conduction from the side surfaces to the ambient air. A linear temperature profile through the core thickness was observed after the specimen had reached the state of heat equilibrium [16]. The temperature of the top face sheet $\left(T_{t}\right)$ was controlled by adjusting the power of the infrared lamp and monitored by a thermocouple. Four temperature cases were experimentally studied in this work with the top face sheet heated to $25^{\circ} \mathrm{C}$, $50^{\circ} \mathrm{C}, 70^{\circ} \mathrm{C}$ and $90^{\circ} \mathrm{C}$, respectively. The corresponding bottom face sheet temperatures $\left(T_{b}\right)$ were measured by a thermocouple and are listed in Table 2. It was observed that the bottom face sheet temperature also increased slightly when the top face sheet was heated. The increase of the bottom face sheet temperature was about $3.5^{\circ} \mathrm{C}$ when the top face sheet temperature increased by $20^{\circ} \mathrm{C}$.

Table 2: Measured temperatures of top and bottom face sheets

\begin{tabular}{|l|l|l|l|l|}
\hline & Case 1 & Case 2 & Case 3 & Case 4 \\
\hline$T_{t}$ & $25^{\circ} \mathrm{C}$ & $50^{\circ} \mathrm{C}$ & $70^{\circ} \mathrm{C}$ & $90^{\circ} \mathrm{C}$ \\
\hline$T_{b}$ & $25^{\circ} \mathrm{C}$ & $31^{\circ} \mathrm{C}$ & $36^{\circ} \mathrm{C}$ & $43^{\circ} \mathrm{C}$ \\
\hline
\end{tabular}

DIC [10] was used to obtain the deflection of the sandwich beam specimen at the mid-span and more importantly to quantitatively assess the 'wavy' deformations of the wrinkled face sheets. DIC calculates the full-field displacement by tracking speckles on a test specimen as it is loaded. To form clear speckles on the specimen, a uniform black layer was firstly prepared on the specimen side surface and then discrete white particles were sprayed on the black layer. During the loading process, images of the side surface of the specimen were recorded using a $16 \mathrm{M}$ pixel resolution camera, and the corresponding load $(P)$ was recorded synchronously. Deformation of the specimen was calculated by performing image correlations between the recorded images using a commercial available software Davis 8.0. By this means, the load-deflection curve to failure of the specimen was obtained. In addition, to capture the occurrence of the predicted face sheet wrinkling, images were also recorded at a frequency of $60 \mathrm{kHz}$ using a PHOTRON FASTCAM SA5 high-speed camera.

The experimental procedure can be summarised as follows: 
Zhang, S., Dulieu-Barton, J.M., and Thomsen, O.T., "The effect of temperature on the failure modes of polymer foam cored sandwich structures", Composite Structures, $\underline{121}, 2015,104-113$.

- The specimen was positioned on the four-point bending jig. The 16 Mega pixel camera was positioned and focused on the side surface of the specimen. The imaging system was calibrated.

- Two foam shields were positioned at the side surfaces of the specimen to minimise heat loss from the side surface.

- The top face sheet was heated to a required temperature as listed in Table 2 and held until an equilibrium state had been reached (this took about half an hour). In this step, the specimen was allowed free thermal expansion.

- The front foam shield was removed, and the bending load was applied until the specimen failed; this procedure only took about 30 seconds and a linear temperature profile could be retained through the core thickness [16]. Images of the specimen side surface and corresponding load data were recorded synchronously.

\section{Results}

All the specimens failed by a sudden collapse, where the core near the mid-span was locally crushed with the face sheet folding into the core as shown in Figure 9(a). The obtained load-deflection curves are shown in Figure 9(b), in which the horizontal axis represents the deflection of the top face sheet at the mid-span and the vertical axis represents the load $P$ (see Figure 2). The legend shows the top and bottom face sheet temperatures for each test. It can be seen that the overall stiffness reduces with increasing temperature. This is as expected because the shear deflection is larger at elevated temperatures due to the reduction in the core shear modulus value. Similarly, the maximum load also decreases with rising temperatures, and the reduction is very significant from $70^{\circ} \mathrm{C}$ to $90^{\circ} \mathrm{C}$. A comparison between the experimental and the expected failure stresses is shown in Figure 10. The solid line (both the bold and thin parts) represents the yield strength of the aluminium face sheet obtained from Figure 3. The dashed line (both the bold and thin parts) represents the critical wrinkling stress obtained by the modification of Plantama's wrinkling analysis. It is important to notice that here the magnitude of the critical wrinkling stresses at elevated temperatures are slightly lower than that shown in Figure 7. The reason for this is that the critical wrinkling stress shown in Figure 7 is obtained assuming that the bottom face sheet temperature is $25^{\circ} \mathrm{C}$, but in the actual experiments the bottom face sheet temperatures were slightly increased as shown in Table 2. In Figure 10, the predicted failure envelope is depicted by the bold (solid and dashed) line, which is a combination of the face sheet yielding curve and the critical wrinkling stress curve intersecting at around $58^{\circ} \mathrm{C}$. The experimental failure stress values for the top face sheet stress agree very well with this trend as shown in Figure 10. Here, two specimens were tested for each temperature, and the test results showed a good repeatability as can be seen in Figure 10. The experimental failure stress of the top face sheet was obtained from the maximum load of each load-deflection curve in Figure 9(b) using the classic 
Zhang, S., Dulieu-Barton, J.M., and Thomsen, O.T., "The effect of temperature on the failure modes of polymer foam cored sandwich structures", Composite Structures, 121, 2015, 104-113.

sandwich beam theory as described in [19]. Although the through thickness temperature gradient causes a core stiffness gradient through the core thickness, the core stiffness variation here is small in comparison to the stiffness of the face sheet which exerts the primary contribution to the bending stiffness of the sandwich beam. Hence the thermal core degradation has marginal effect on the position of the neutral plane of the sandwich beam, and thus the classic sandwich beam theory is still appropriate to be used to calculate the face sheet stress.

To further examine the occurrence of face sheet wrinkling for the specimen tested at $90^{\circ} \mathrm{C}$, high-speed imaging was used in an attempt to capture the face sheet wrinkling wave. Images of the specimen deformation were recorded by a PHOTRON FASTCAM SA5 camera at a high frequency of $60 \mathrm{kHz}$. One typical series of specimen images recorded near the occurrence of face sheet wrinkling is shown in Figures 11 (a), (b) and (c). Figure 1(a) is an image just before the occurrence of wrinkling. Figure $11(\mathrm{~b})$ and $11(\mathrm{c})$ are the next two images captured at $17 \mu \mathrm{s}$ and $34 \mu \mathrm{s}$, respectively, after the first image. The image in Figure 11 (a) was used as the reference image for the DIC. The $z$ direction displacement is shown in Figure 12(a) and Figure 12(b), respectively, and clearly shows the wavy deformation of the top face sheet. This wavy deformation is further illustrated in Figure 13(a), where the $z$ direction displacement along the top face sheet near the wrinkle is plotted. It is observed that, at $17 \mu \mathrm{s}$, the displacement of the top face sheet was in a very regularly sinusoidal shape, which indicates that the face sheet was buckled and the deformation was still in the material elastic region. However, at $34 \mu \mathrm{s}$, the wavy deformation of the face sheet became irregular, where the magnitude of the wave crest is much larger than the wave trough. This is caused by the core crushing (see Figure 11(c)) at the wave crest due to development of large compressive stresses. Meanwhile, debonding between the face sheet and the core was also observed at the wave trough which is likely to be induced due by the large peeling stresses present here. Figure 13(b) shows the variation of the amplitude of the wavy

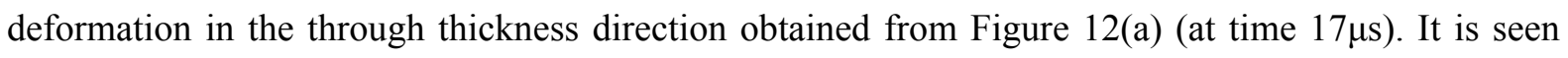
that the variation of the amplitude is fairly close to an exponential function, thus confirming that the baseline assumption about the decay of the face deflections through the core thickness adopted by Plantema [7] and discussed in Section 2 is physically meaningful. Hence, the wavy deformation of the face sheet which represents the occurrence of wrinkling was successfully observed using the highspeed imaging combined with DIC. The wavy deformation triggered a very quick core crushing (within tens of $\mu \mathrm{s}$ ) and this makes high-speed imaging essential and indeed necessary to capture the wrinkling behaviour.

The face sheet wavy deformation was observed not only for the specimens tested at $90^{\circ} \mathrm{C}$, but also for the specimens tested at $25^{\circ} \mathrm{C}, 50^{\circ} \mathrm{C}$ and $70^{\circ} \mathrm{C}$. This seems to contradict the prediction that the specimen should fail by face sheet yielding at temperatures lower than $58^{\circ} \mathrm{C}$ as shown in Figure 10 . However, the specimen collapses observed at $25^{\circ} \mathrm{C}$ and $50^{\circ} \mathrm{C}$ can still be explained by initiation of 
Zhang, S., Dulieu-Barton, J.M., and Thomsen, O.T., "The effect of temperature on the failure modes of polymer foam cored sandwich structures", Composite Structures, 121, 2015, 104-113.

face sheet yielding despite of the observed wavy deformations. The reason simply is that for the face sheet material (AA7075-T6) significant stiffness reduction is encountered when yielding is initiated, and provokes wrinkling instability. To confirm this hypothesis, the $x$ direction compressive strain of the top face sheet just before the specimen collapse was obtained using DIC on the images recorded by the high resolution camera. The $x$ direction strain of the top face sheet over the span $L 2$ (see Figure 2) should be uniform according to the sandwich beam theory. Accordingly, the compressive strain was obtained as the average measured strain over a length of $50 \mathrm{~mm}$ near the mid-span. The stress value corresponding to the measured (averaged) compressive strain was obtained from the tensile stress-strain curves shown in Figure 3. The stress-strain states of the top face sheet of sandwich beam specimens before collapse are depicted in Figure 14, where the stress-strain curves of the face sheet at different temperatures are also plotted. For convenience, here the compressive stress and strain values of the top face sheet were given positive values instead of negative values as is usually done for compressive data. It can be seen that for the sandwich beam specimen tested at $25^{\circ} \mathrm{C}$, the face sheet stress was beyond the elastic limit before the specimen failed. This indicates that the specimen failure was initiated by face sheet yielding followed by plastic instability. This can also be confirmed from the load-deflection curve shown in Figure 9(b), where a nonlinear region exists before the specimen collapse which is due to the fact that face sheet yielding results in a reduced overall bending stiffness of the sandwich beam specimen. The sequence of events for this failure mechanism is: (1) small scale face sheet yielding due to essentially uniform compressive face sheet stresses and leading to a reduction of the face sheet tangent modulus (an thereby a reduction to the effective face sheet bending stiffness, (2) wrinkling of the face sheet, (3) large plastic deformation of the face sheet and core, and finally (4) collapse of the specimen. For the sandwich beam specimens tested at $70^{\circ} \mathrm{C}$ and $90^{\circ} \mathrm{C}$, Figure 14 shows that the face sheet was still in a linear elastic condition prior to collapse. This proves that the face sheet failed by elastic instability or wrinkling. The sequence of events for this failure mechanism is: (1) elastic wrinkling of the face sheet, (2) large plastic deformation of the face sheet and core, and finally (3) collapse of the specimen. For the sandwich beam specimens tested at $50^{\circ} \mathrm{C}$, before the specimen collapse the face sheet may have started to yield but with a small magnitude. This indicates that $50^{\circ} \mathrm{C}$ is close to the temperature which marks a transition of the critical failure mode from face sheet yielding to wrinkling. All the specimen failure modes observed at different temperatures agree very well with the predictions of the modified Plantema wrinkling analysis as shown in Figure 10. The magnitude of the critical wrinkling stress obtained in the experiments is slightly lower than the analytical predictions. A plausible explanation for this could be the influence of initial imperfections such as face sheet waviness [20] or bonding defects. In Figure 10, the magnitude of the failure stress of the top face sheet by yielding is also slightly lower than the actual material yield strength. The reason for this is that the yield strength was obtained as the stress at the 
Zhang, S., Dulieu-Barton, J.M., and Thomsen, O.T., "The effect of temperature on the failure modes of polymer foam cored sandwich structures", Composite Structures, 121, 2015, 104-113.

$0.2 \%$ plastic strain, where the tangent modulus is nearly zero, and hence plastic instability must occur at a lower stress.

In addition, not only the critical wrinkling stress but also the wavelength of the wrinkle is provided by the experimental technique, as can be seen from Figure 13. In Figure 13, the measured wavelength is about $9 \mathrm{~mm}$, while that obtained from the analytical model is $12.5 \mathrm{~mm}$ (see Equation (10)). Albeit the predicted and measured wave lengths are comparable in magnitude, this is a rather large discrepancy, and much larger than the discrepancies between the predicted and measured critical stress values which are very close. The explanation is likely to be a combination of several factors including the validity of the fundamental assumptions behind the Plantema wrinkling analysis which assumes a constant wave length and exponential decay response, the relatively low image resolution, coupling between the wrinkling and plastic deformation, and finally probable material heterogeneousity in the both the length and through thickness directions.

\section{Conclusions}

The influence of elevated temperature on the stability of foam cored sandwich structures has been studied analytically and experimentally. A new analytical model has been proposed to calculate the critical wrinkling stress of sandwich structures when a temperature gradient (thus a stiffness gradient) exists though the core thickness. The new model is based on Plantema's classic wrinkling analysis [8], but here the stiffness variation in the transverse direction is considered, and a simple and easy to use formula has been derived to calculate the critical wrinkling stress. This modification of Plantema's wrinkling analysis agrees very well with corresponding FE modelling and experimental results.

An experimental apparatus has been established enabling investigation of sandwich beam specimens subjected to a simultaneous simply supported four-point bending load and a linear temperature gradient through the thickness. High-speed imaging combined with DIC has been demonstrated to provide a good approach to assess the occurrence and rapid evolution of face sheet wrinkling. For the particular sandwich beam specimen considered, it has been experimentally observed that the specimens failed by face sheet yielding at room temperature and by wrinkling (instability) when the top face sheet is heated to $70^{\circ} \mathrm{C}$ or higher. This failure mode shift corresponds well with the predictions by Frostig and Thomsen [4] and Birman [7].

Thermally induced stresses have not been discussed in this paper, but in principle the thermally induced stresses can be obtained if the material thermal expansion coefficients, the mechanical boundary conditions, and the thermal field imposed are known [7]. The temperature dependence of the face sheet properties is barely discussed in this work, but it could be significant if the temperature is very high (i.e. over $100^{\circ} \mathrm{C}$ ) for normal e.g. GFRP (glass fibre reinforced plastic) or CFRP (carbon fibre reinforced plastic) face sheets. 
Zhang, S., Dulieu-Barton, J.M., and Thomsen, O.T., "The effect of temperature on the failure modes of polymer foam cored sandwich structures", Composite Structures, 121, 2015, 104-113.

To the authors' knowledge, the present paper for the first time experimentally demonstrates that an elevated temperature environment can promote an unstable failure mode in polymer foam cored sandwich structures at much smaller loads than that predicted by material failure.

\section{Acknowledgments}

The work presented was co-sponsored by the Chinese Scholarship Council, the Danish Council for Independent Research | Technology and Production Sciences (FTP), Grant Agreement 274-08-0488, "Thermal Degradation of Polymer Foam Cored Sandwich Structures", and the US Navy, Office of Naval Research (ONR), Grant Award N000140710227. The ONR programme manager was Dr. Yapa D. S. Rajapakse. The financial support received is gratefully acknowledged.

\section{Reference}

1. DATAFORTH. Wind Turbines Today Enhanced Reliability with Dataforth Signal Conditioners.[cited $2012 \quad 03 \quad$ November]; Available from: http://www.dataforth.com/catalog/pdf/Wind_Turbines Today.pdf.

2. Gibson L. and Ashby M., Cellular Solids: Structure and Properties. 1999, Cambridge: Cambridge University Press.

3. Zhang S., Dulieu-Barton J., Fruehmann R. and Thomsen O., A Methodology for Obtaining Material Properties of Polymeric Foam at Elevated Temperatures. Experimental Mechanics, 2012. 52(1): p. 3-15.

4. Frostig Y. and Thomsen O.T., Non-linear Thermal Response of Sandwich Panels with a Flexible Core and Temperature Dependent Mechanical Properties. Composites Part B: Engineering, 2008. 39(1): p. 165-184.

5. Frostig Y. and Thomsen O.T., Thermal Buckling and Postbuckling of Sandwich Panels with a Transversely Flexible Core. Aiaa Journal, 2008. 46(8): p. 1976-1989.

6. Frostig Y. and Thomsen O.T., On theFree Vibration of Sandwich Panels with a Transversely Flexible and Temperature-dependent Core Material - Part I: Mathematical Formulation. Composites Science and Technology, 2009. 69(6): p. 856-862.

7. Birman V., Thermally Induced Bending and Wrinkling in Iarge Aspect Ratio Sandwich Panels. Composites Part A: Applied Science and Manufacturing, 2005. 36(10): p. 1412-1420.

8. Plantema F.J., Sandwich Construction. 1966, New York: John Wiley \& Sons.

9. Fagerberg L. and Zenkert D., Effects of Anisotropy and Multiaxial Loading on the Wrinkling of Sandwich Panels. Journal of Sandwich Structures \& Materials, 2005. 7(3): p. 177-194.

10. Sutton M.A., Orteu J.-J. and Schreier H.W., Image Correlation for Shape, Motion and Deformation Measurements. 2009, New York: Springer Science+Business Media.

11. Allen H.G., Analysis and Design of Sandwich Structure Panels. 1969, Oxford: Pergamon Press.

12. Hoff N.J. and Mautner S.F., The Buckling of Sandwich-Type Panels. Journal of Aeronautical Sciences, 1945. 12: p. 285-297.

13. ASTM-E8, Standard Test Methods for Tension Testing of Metallic Materials. 2007.

14. Robinson A., Dulieu-Barton J., Quinn S. and Burguete R., The Potential for Assessing Residual Stress Using Thermoelastic Stress Analysis: A Study of Cold Expanded Holes. Experimental Mechanics, 2013. 53(2).

15. Zhang S., Dulieu-Barton J.M., Fruehmann R.K. and Thomsen O.T., Thermal Degradation of Polymeric Foam Core Materials for Sandwich Structures, in The 18th International Conference on Composite Materials. 2011: Jeju, Korea. 
Zhang, S., Dulieu-Barton, J.M., and Thomsen, O.T., "The effect of temperature on the failure modes of polymer foam cored sandwich structures", Composite Structures, 121, 2015, 104-113.

16. Fruehmann R.K., Dulieu-Barton J.M., Thomsen O.T. and Zhang S., Experimental Investigation of Thermal Effects in Foam Cored Sandwich Beams, in Thermomechanics and Infra-Red Imaging, Volume 7. 2011, Springer New York. p. 83-90.

17. ASTM-D7249, Standard Test Method for Facing Properties of Sandwich Constructions by Long Beam Flexure. 2006.

18. Xue L. and Wierzbicki T., Ductile Fracture Characterisation of Aluminium Alloy 2024T351 Using Damage Plasticity Theory. International Journal of Applied Mechanics, 2009. 1(2): p. 267-304.

19. Zenkert D., An Introduction To Sandwich Construction. 1995, London: Chameleon Press.

20. Ley R.P., Lin W. and Mbanefo L., Face-sheet Wrinkling in Sandwich Structures in Report: NASA/CR-1999-208994. 1999, National Areronautics and Space Adminsistration Virginia 


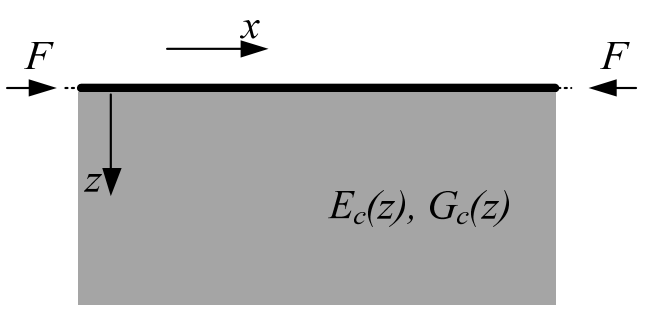

(a) before wrinkling

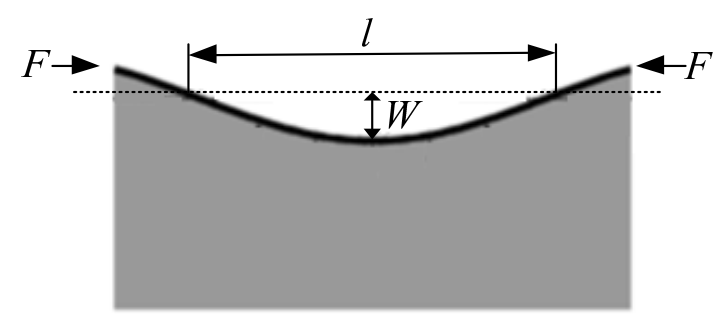

(b) after wrinkling

Figure 1: schematic of wrinkling

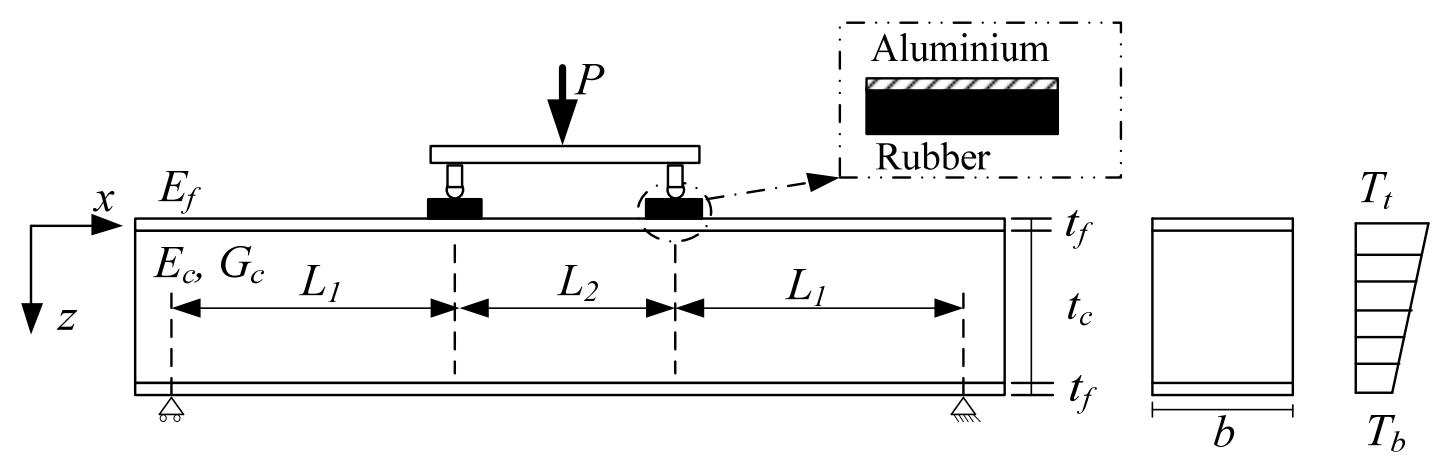

Figure 2: Schematic of 4-point bending test of sandwich beam with a through thickness temperature gradient 


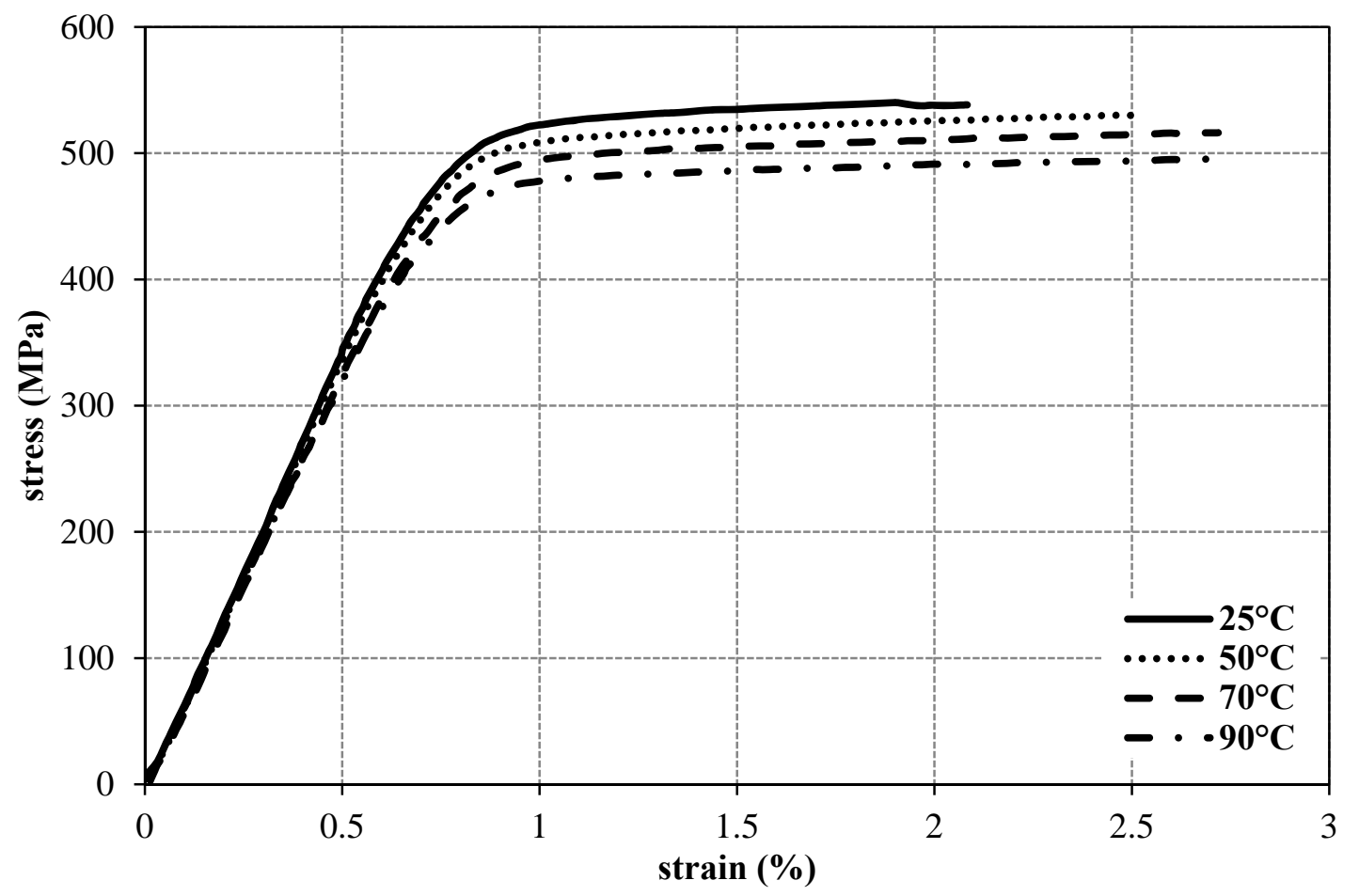

Figure 3: Temperature dependence of stress-strain curve of aluminium alloy 7075-T6

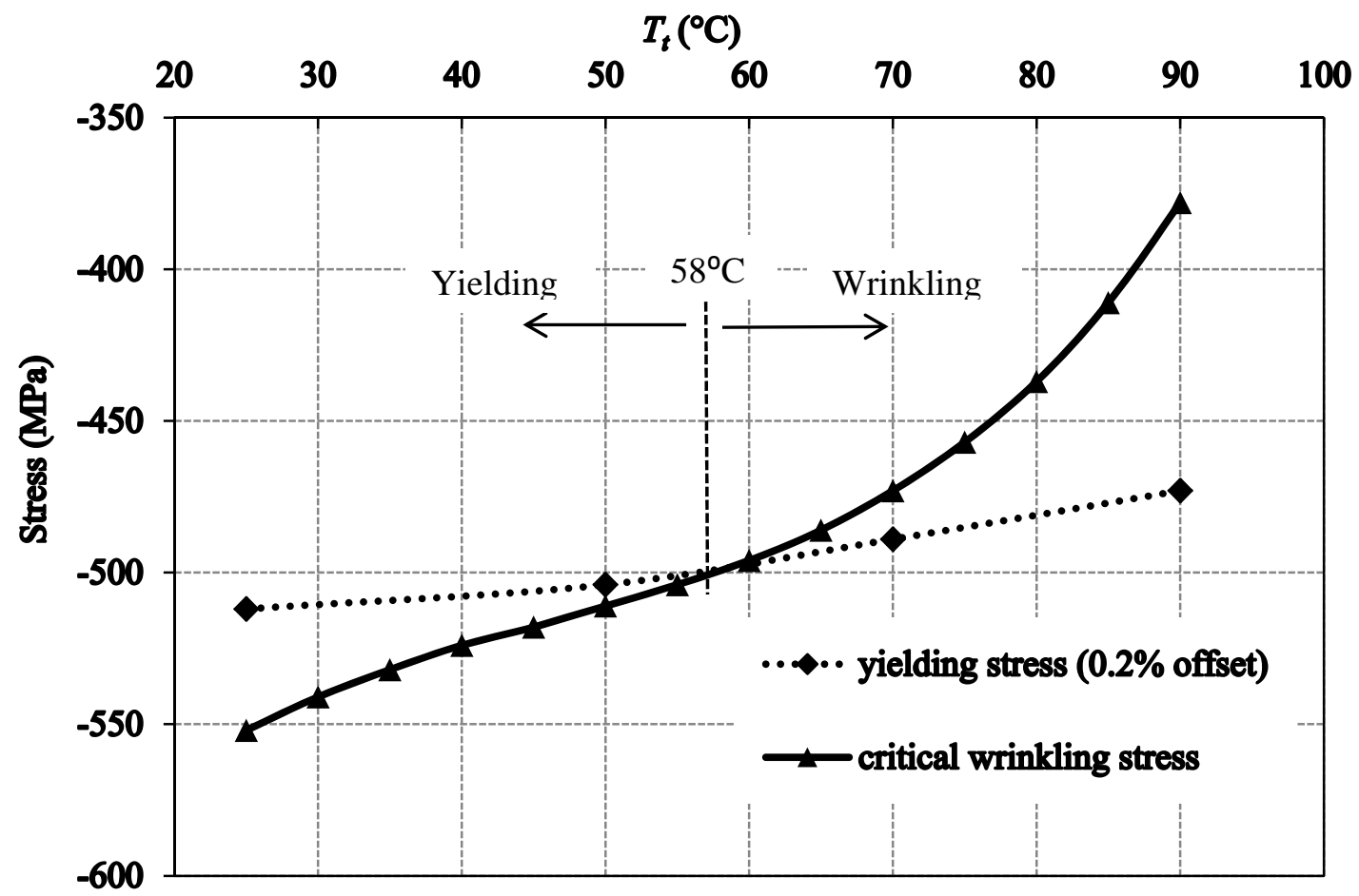

Figure 4: A comparison of the critical wrinkling stress and yielding stress of the face-sheet 


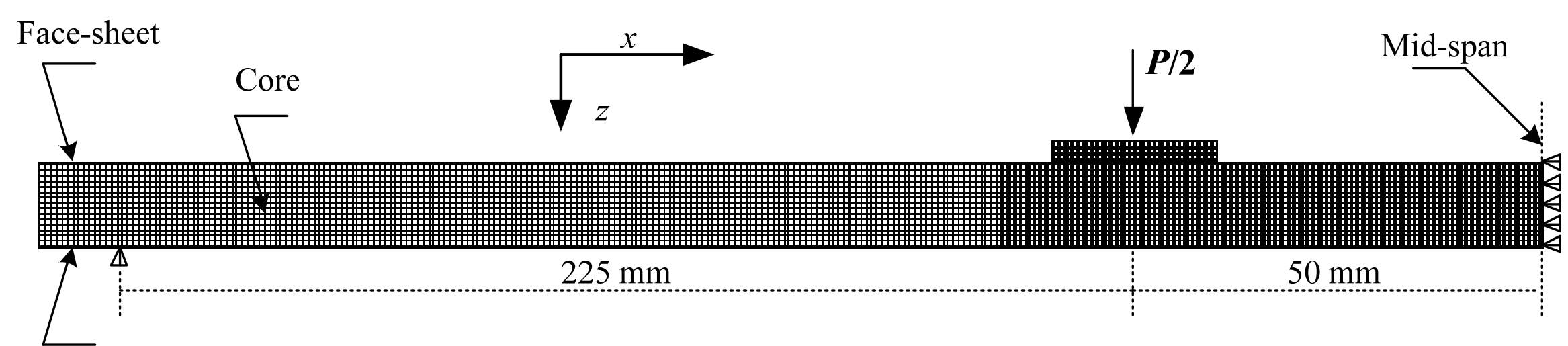

Face-sheet

Figure 5: Finite element model showing geometrical model, FE mesh, imposed boundary conditions and load application 


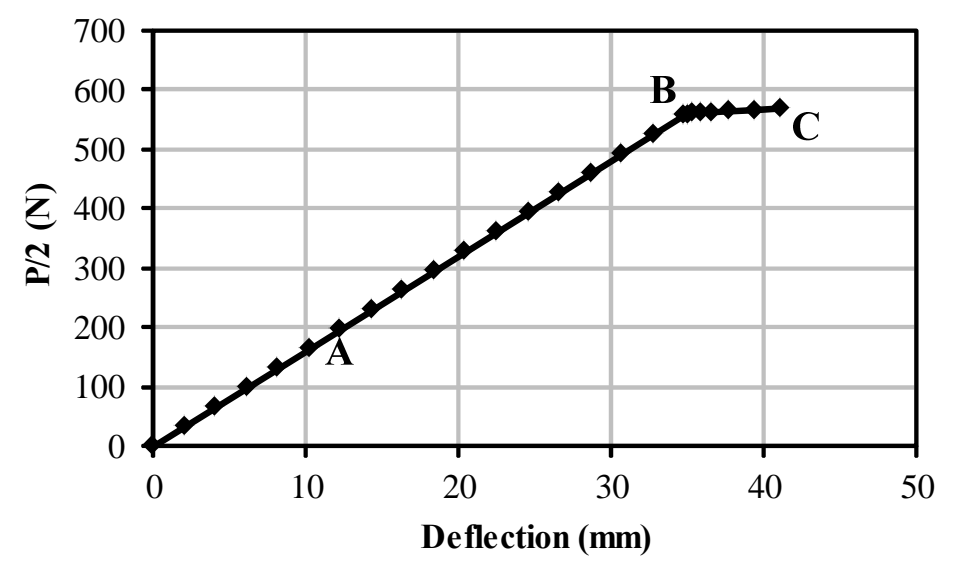

(a) load-defection curve

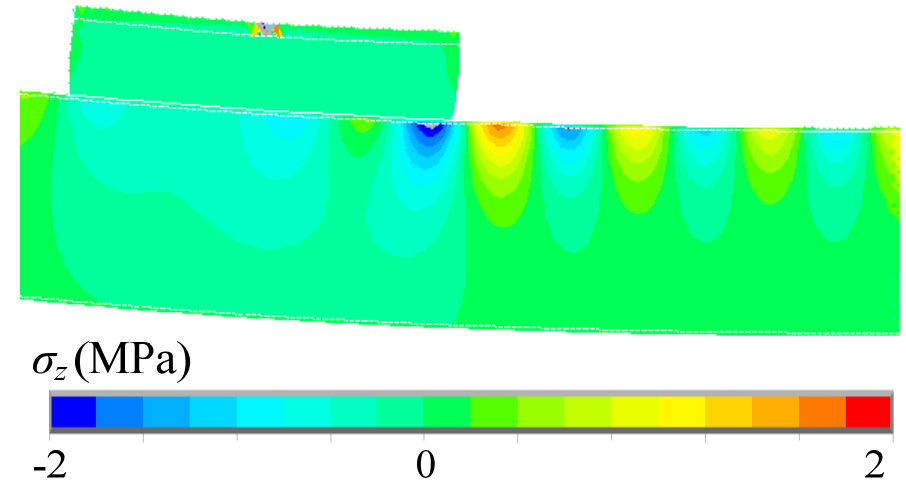

(c) $\sigma_{z}$ at starting of wrinkling (point B)

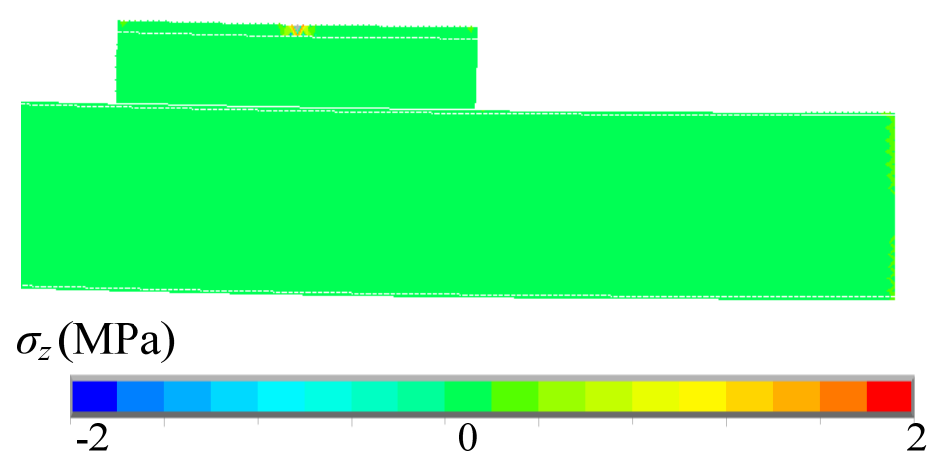

(b) $\sigma_{z}$ at linear stage (point A)

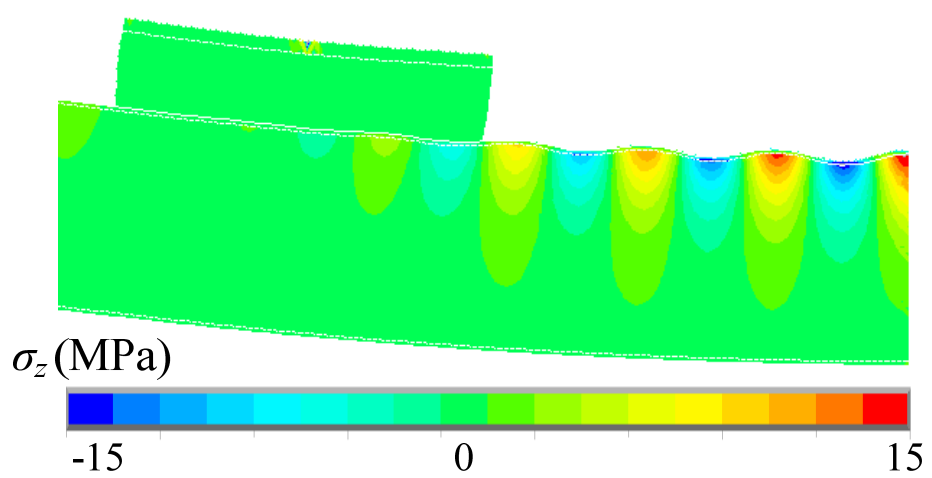

(d) $\sigma_{z}$ at post wrinkling (point C)

Figure 6: Load-deflection curve obtained by FE and the deformed shape and transverse normal stress distributions at loading stages A, $B$ and $C$ 


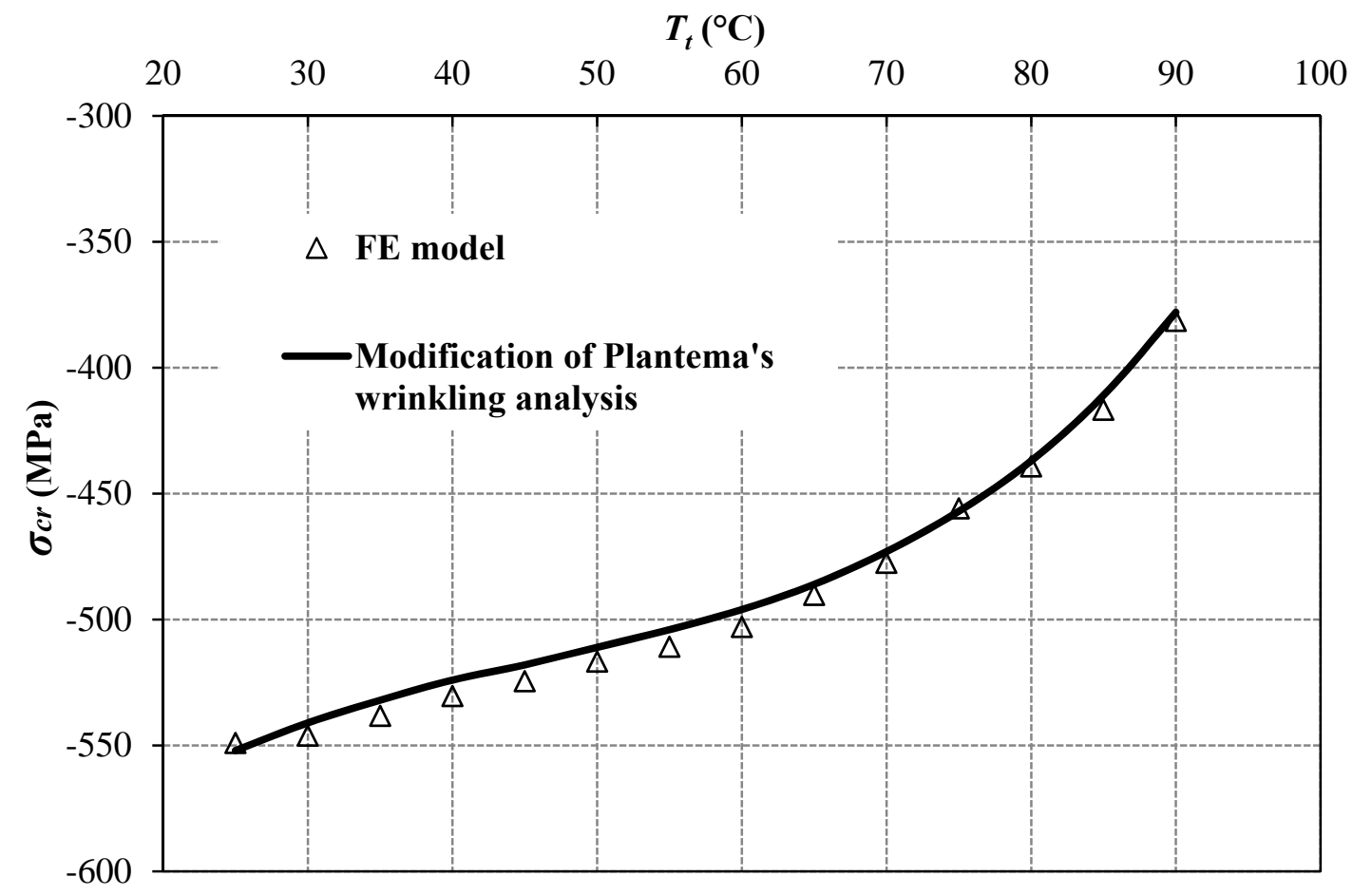

Figure 7: Critical wrinkling stress obtained using FE and analytical method for different temperatures at the top face-sheet 


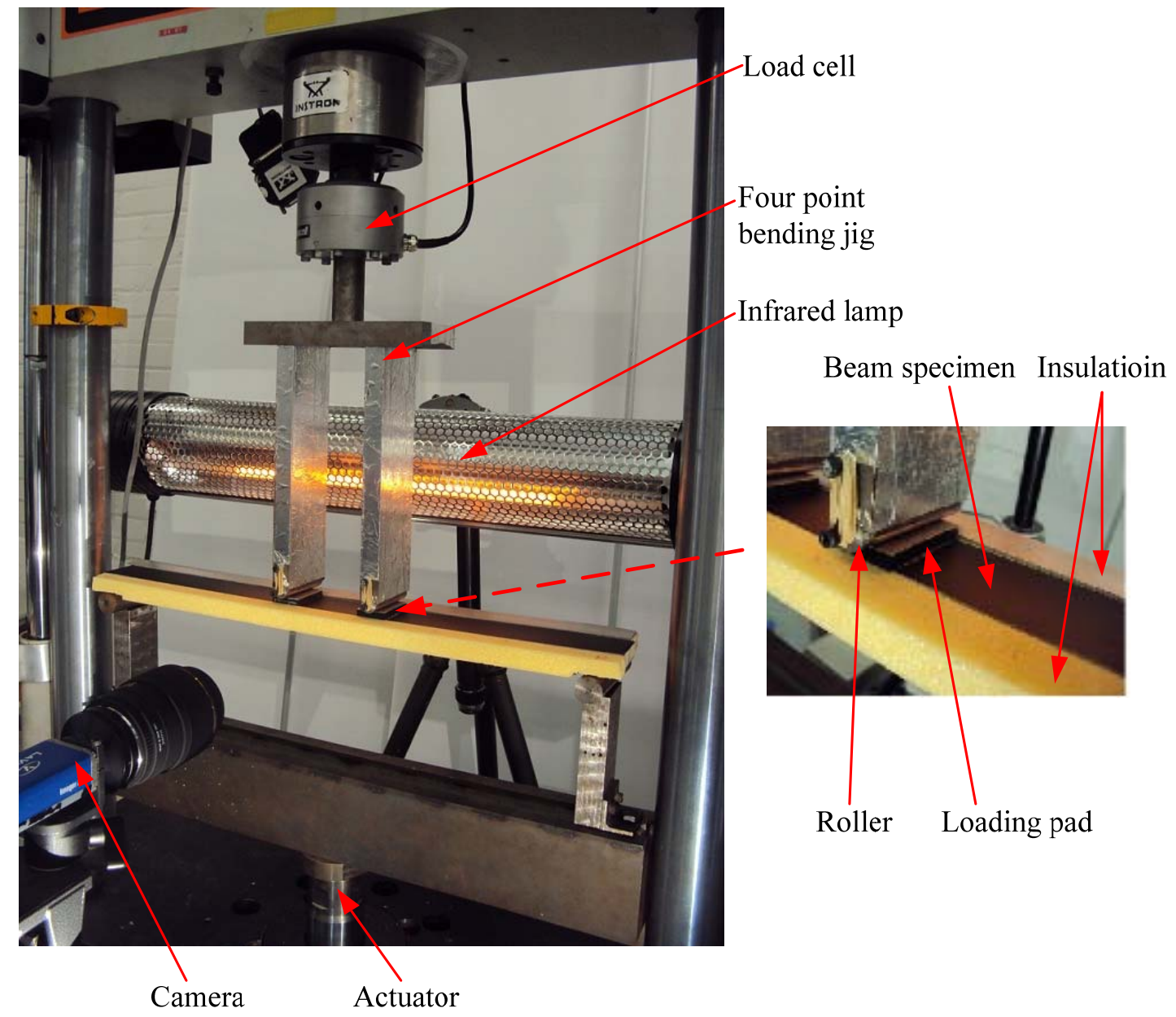

Figure 8: Experimental set-up 


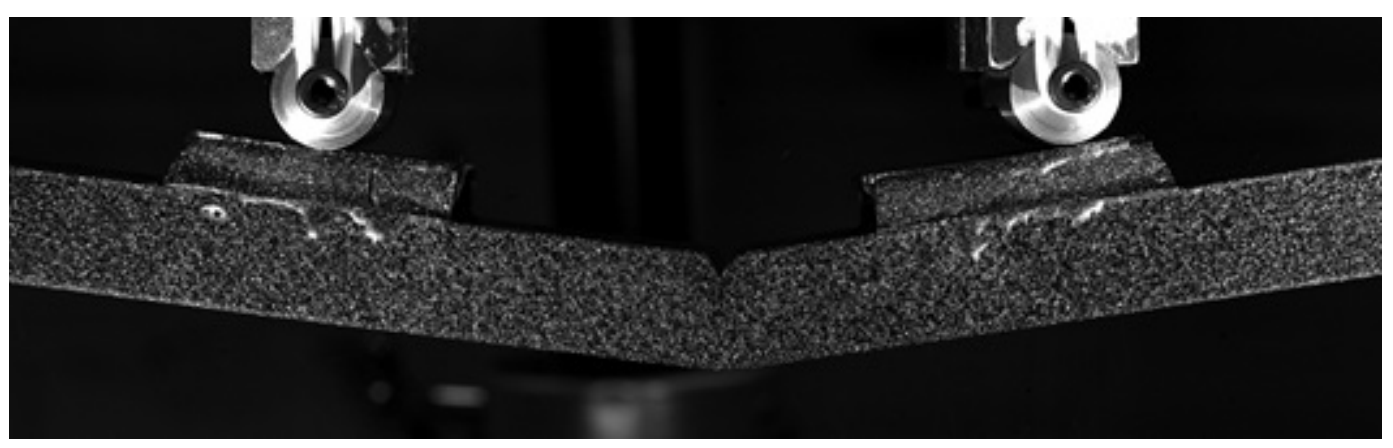

(a)

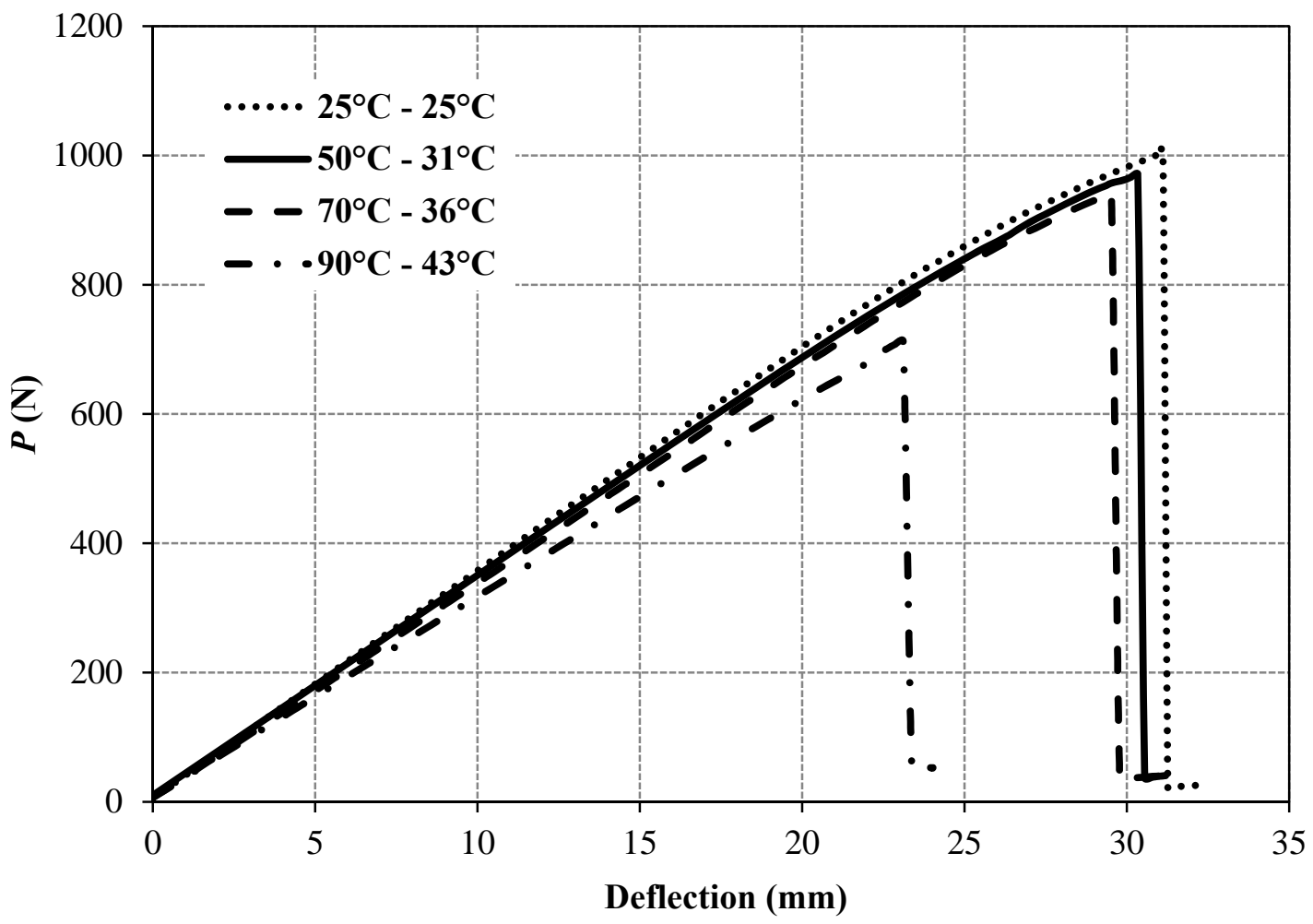

(b)

Figure 9: (a) Final failure shape of the specimen; (b) load-deflection curve of sandwich beam specimen at different temperatures 


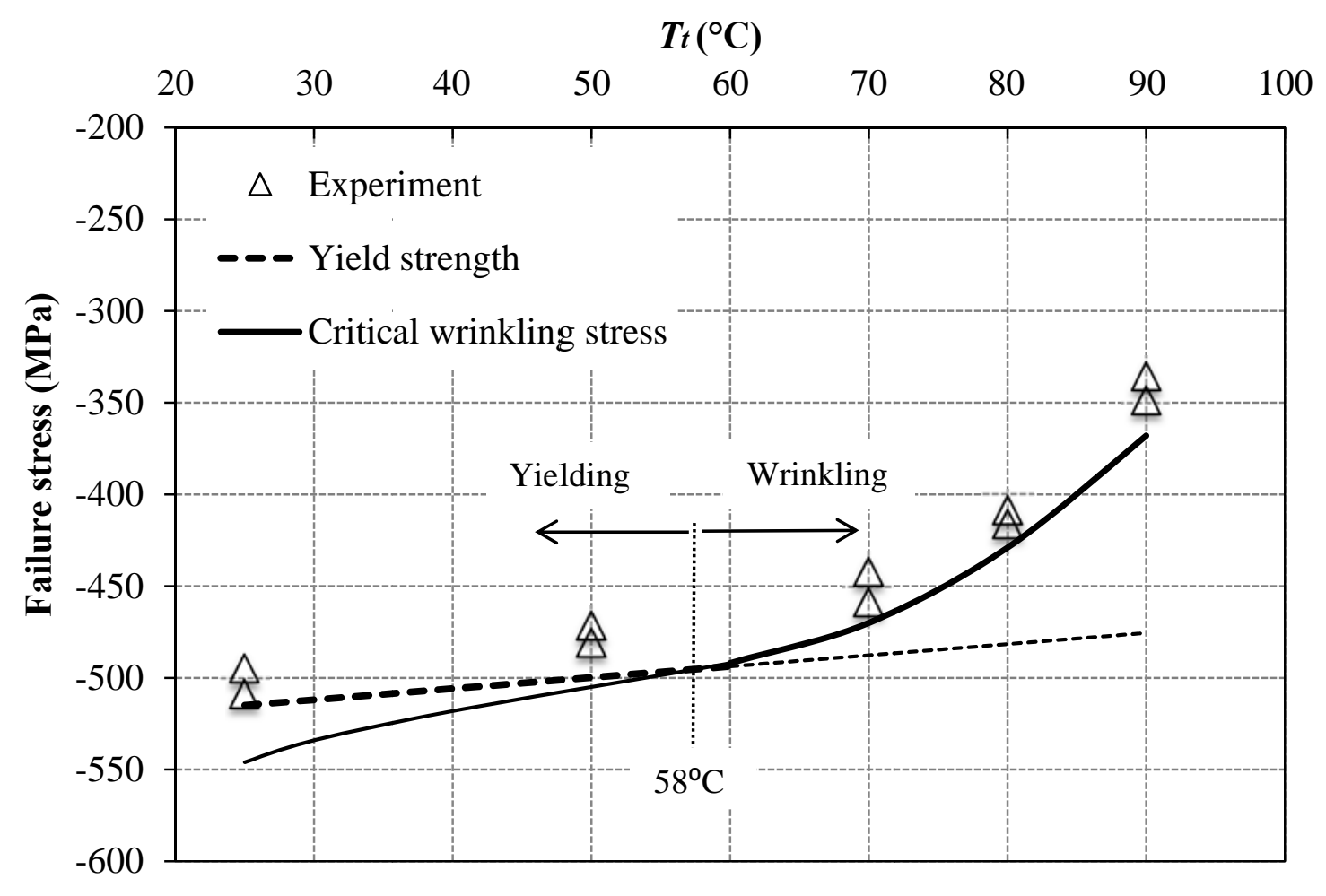

Figure 10: Comparison between the predicted failure stresses and the experimental results 


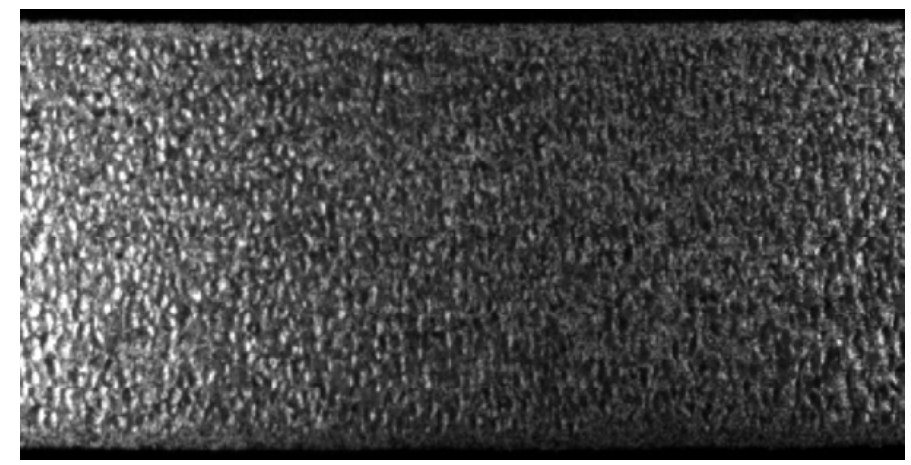

(a) Just before wrinkling $(\mathrm{t}=0)$

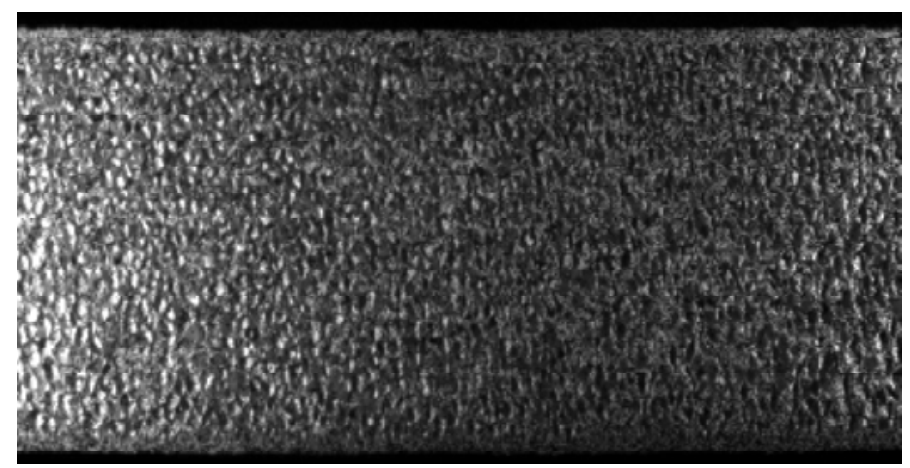

(b) Elastic wrinkling $(\mathrm{t}=17 \mu \mathrm{s})$

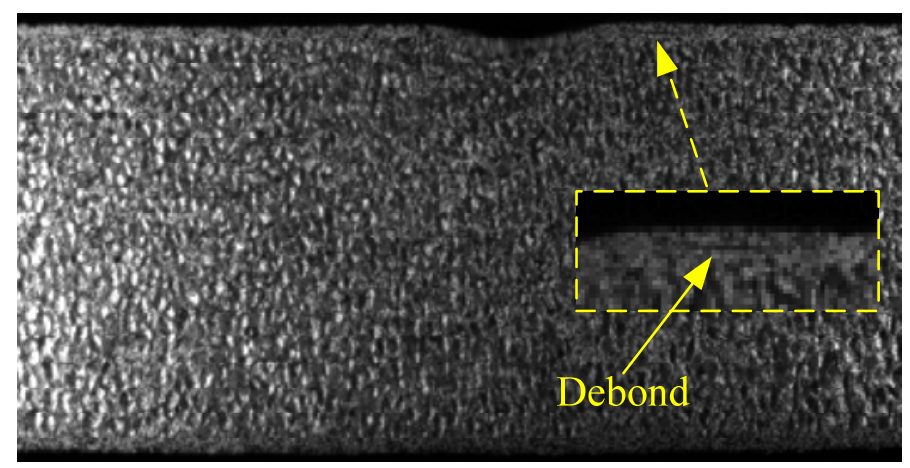

(c) Core crushing $(\mathrm{t}=34 \mu \mathrm{s})$

Figure 11: Images of the specimen immediately before and after the onset of wrinkling. 


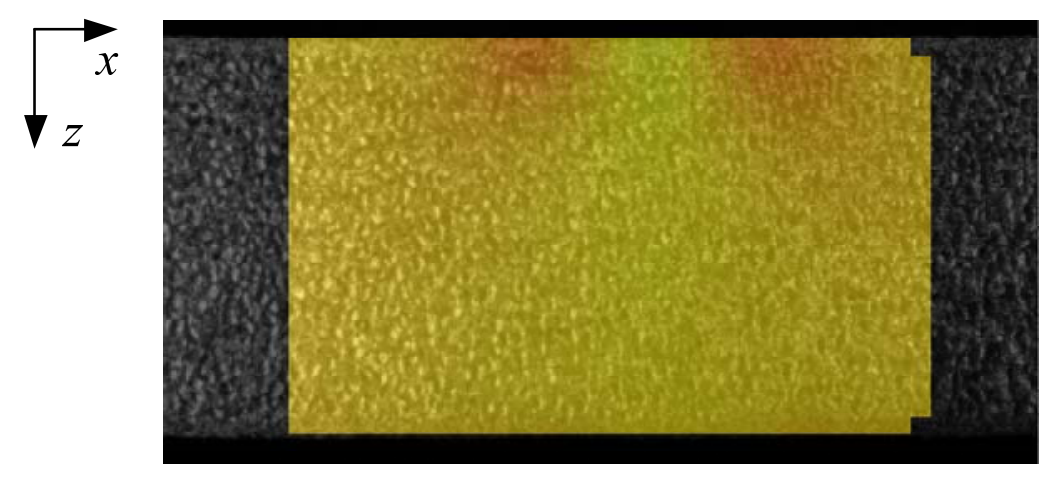

(a) $v_{z}$ at $\mathrm{t}=17 \mu \mathrm{s}$

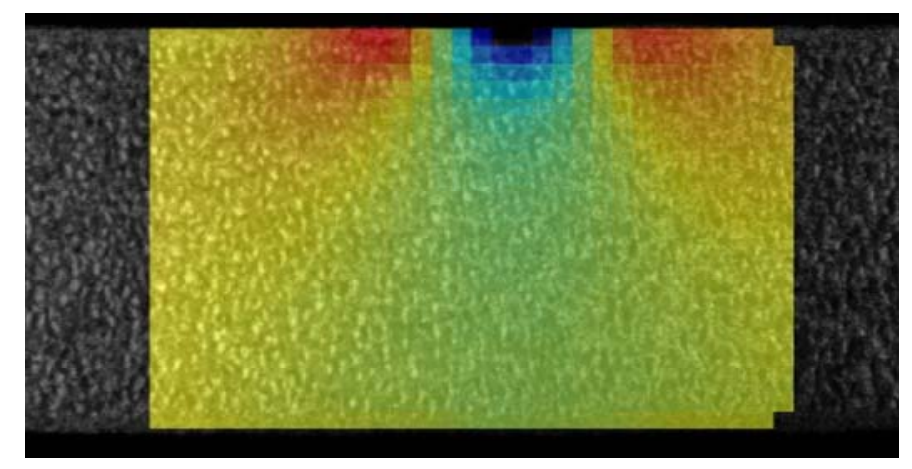

(b) $v_{z}$ at $\mathrm{t}=34 \mu \mathrm{s}$

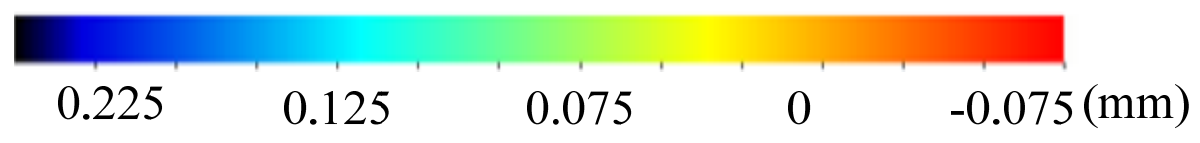

Figure 12: $z$ direction displacement contour of the specimen at times $17 \mu$ s and 34 $\mu \mathrm{s}$. 


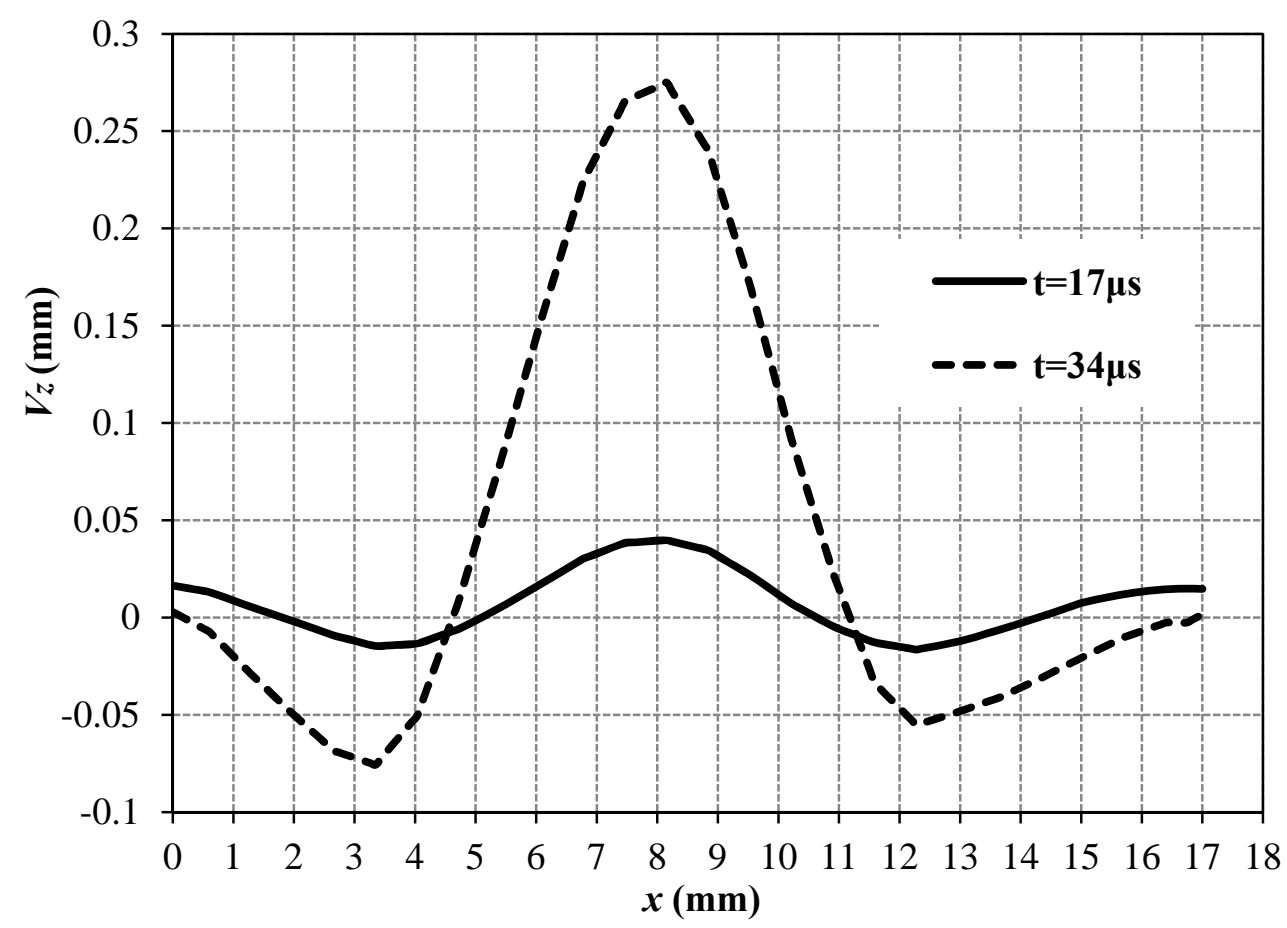

(a)

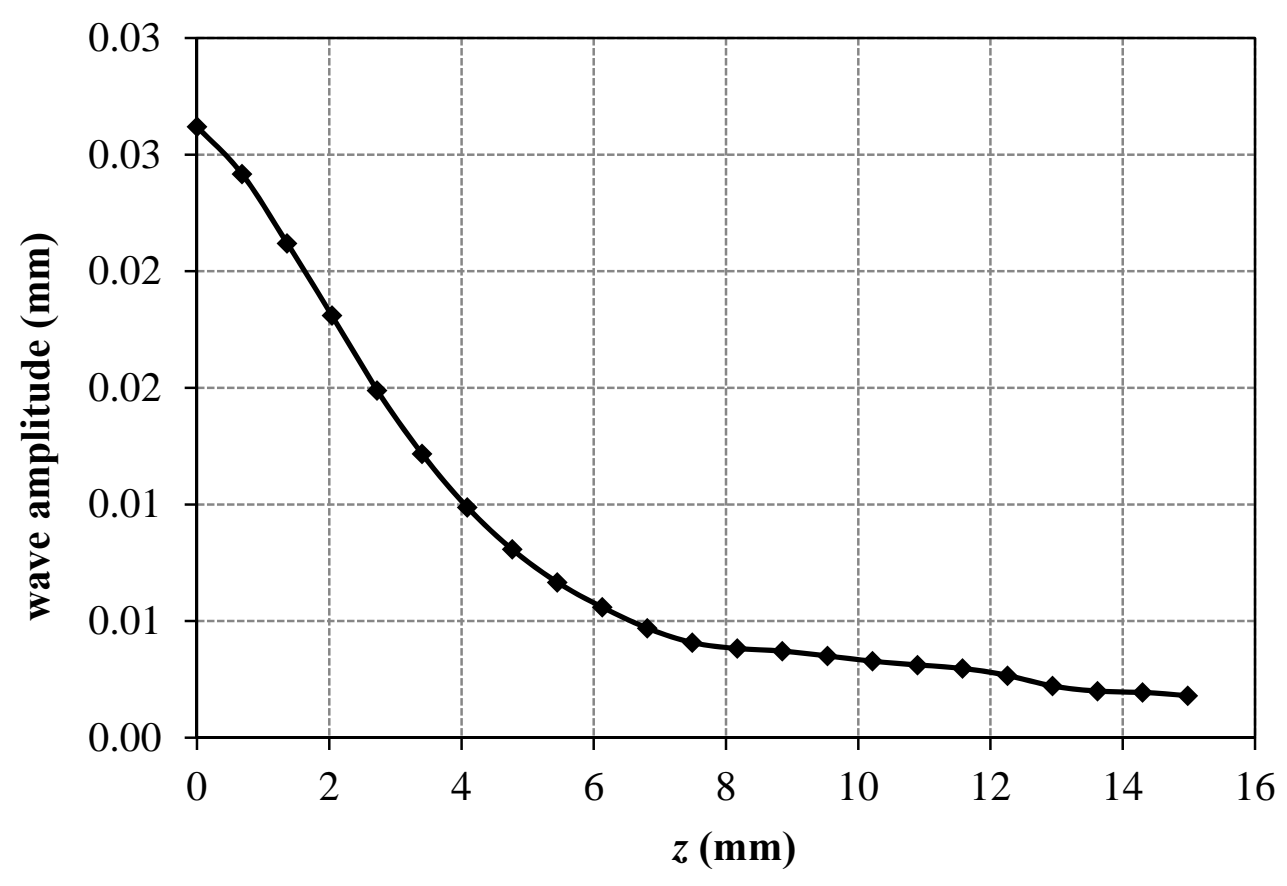

(b)

Figure 13: (a) $z$ direction displacement of the top face sheet at time $17 \mu$ s and 34 $\mu s$; (b) the variation of the amplitude of the wavy deformation through the core thickness at time $17 \mu \mathrm{s}(z=0$ : top face sheet; $z=15$ : bottom face sheet $)$ 


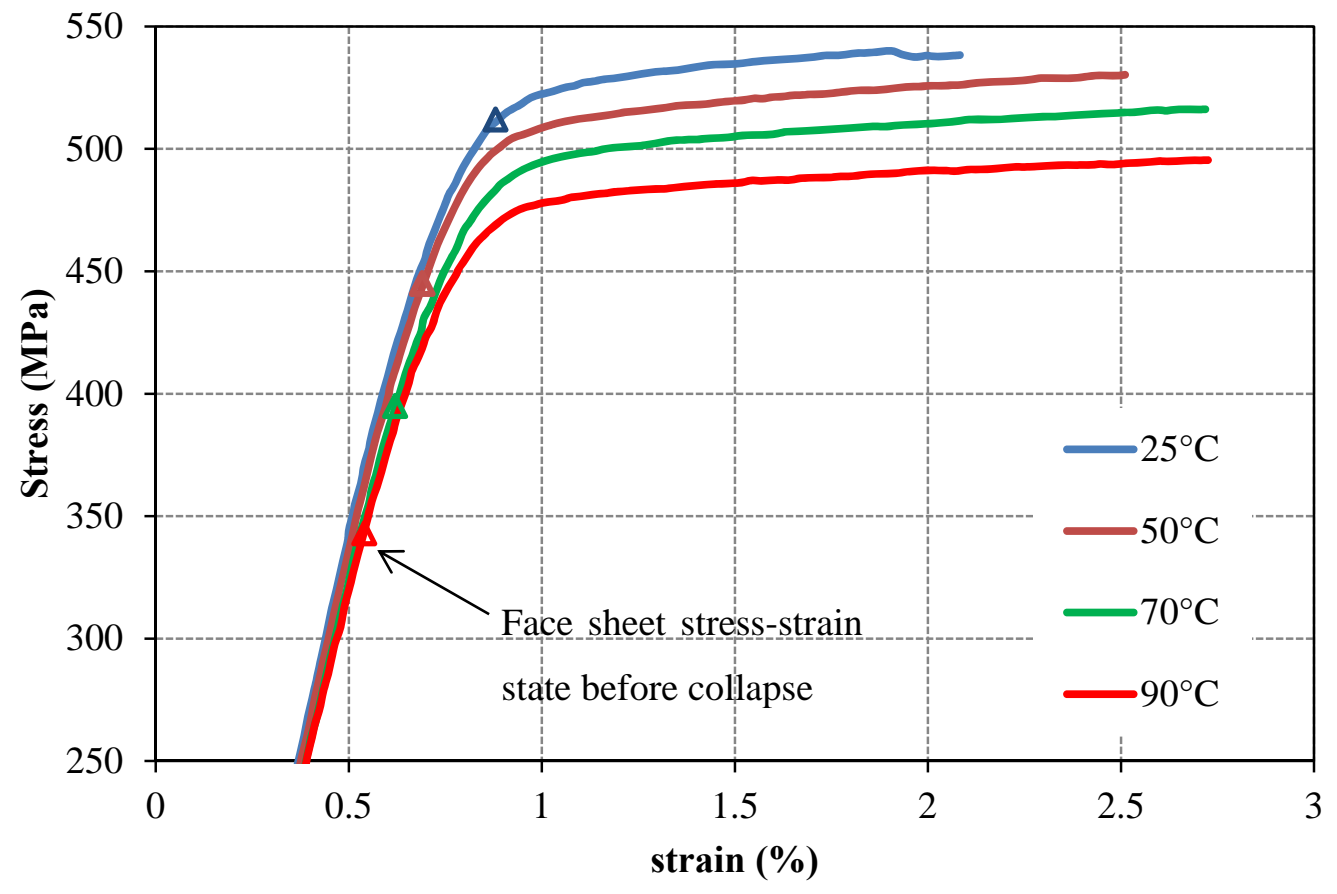

Figure 14: Stress-strain state of the face sheets (aluminium alloy, AA7075-T6) of sandwich beam specimens before core collapse.

Table 1: Material properties at room temperature $\left(25^{\circ} \mathrm{C}\right)$

\begin{tabular}{|l|l|l|l|l|}
\hline & $E_{\mathrm{z}}(\mathrm{MPa})$ & $E_{\mathrm{x}}(\mathrm{MPa})$ & $G_{\mathrm{zx}}(\mathrm{MPa})$ & $v_{\mathrm{zx}}$ \\
\hline AA7075-T6 & 69100 & 69100 & 26576 & 0.3 \\
\hline Divinycell H100 & 132 & 58 & 32 & 0.4 \\
\hline
\end{tabular}

Table 2: Measured temperatures of top and bottom face sheets

\begin{tabular}{|l|l|l|l|l|}
\hline & Case 1 & Case 2 & Case 3 & Case 4 \\
\hline$T_{t}$ & $25^{\circ} \mathrm{C}$ & $50^{\circ} \mathrm{C}$ & $70^{\circ} \mathrm{C}$ & $90^{\circ} \mathrm{C}$ \\
\hline$T_{b}$ & $25^{\circ} \mathrm{C}$ & $31^{\circ} \mathrm{C}$ & $36^{\circ} \mathrm{C}$ & $43^{\circ} \mathrm{C}$ \\
\hline
\end{tabular}

